\title{
Context in Continuity: The Enduring Legacy of Neighborhood Disadvantage Across Generations
}

\author{
Steven Elías Alvarado ${ }^{1}$ \\ Alexandra Cooperstock \\ Cornell University \\ Citation: \\ Alvarado, S.E. and Alexandra Cooperstock. 2021. "Context in Continuity: The Enduring Legacy of \\ Neighborhood Disadvantage Across Generations.” Research in Social Stratification and Mobility.
}

\begin{abstract}
:
Neighborhoods may contribute to the maintenance of inequality in well-being across generations. We use 35 years of restricted geo-coded NLSY 1979 and NLSY Children and Young Adults data to estimate the association between multigenerational exposure to childhood neighborhood disadvantage and subsequent adult exposure. Invoking cousin fixed effects models that adjust for unobserved legacies of disadvantage that cascade across generations, we find that families where both parents and their children are exposed to childhood neighborhood disadvantage are likely to pass on the legacy of neighborhood disadvantage to successive generations, net of observed and unobserved confounders. Second, we find a direct intergenerational neighborhood association, net of observed and unobserved confounders. Third, we find that unobserved confounders nested in previous generations explain away the intragenerational neighborhood association. These findings reorient neighborhood theory to more seriously attend to the interdependence of neighborhood level and individual level antecedents of inequality across generations.
\end{abstract}

\section{Keywords:}

neighborhood disadvantage, spatial mobility, inequality, cousin fixed effects

Acknowledgements: All analyses rely on restricted tract-level NLSY data with special permission from the U.S. Department of Labor and were completed on encrypted machines at Bureau of Labor Statistics (BLS) headquarters in Washington, D.C. The views expressed here do not necessarily reflect the views of the BLS. A version of this paper was presented at the 2019 Population Association of America conference in Austin, Texas. The authors thank Adam Gamoran and Marta Tienda for helpful comments on revision memos, Florio Arguillas for coding assistance, and various anonymous reviewers for their helpful suggestions. All errors belong to the authors alone.

\footnotetext{
${ }^{1}$ Direct correspondence to: Steven Elías Alvarado, Cornell University, Department of Sociology, 336 Uris Hall, Ithaca, New York, 14853. Email: alvarado@cornell.edu; Phone: 607.255.6289; Fax: 607.255.8473.
} 


\section{Introduction}

Neighborhood context proves stubbornly difficult to escape in the United States. Numerous studies document the rigidity of the American residential mobility structure (Crowder and Downey, 2010; Crowder and South, 2005; Quillian, 2003; Sharkey, 2008; South and Crowder, 1997; Timberlake, 2007, 2009a, 2009b) and how exposure to socioeconomically disadvantaged neighborhoods can diminish well-being (Alvarado, 2016a, 2020; Chetty et al., 2016, 2018; Diez-Roux and Mair, 2010; Manduca and Sampson, 2019; Sampson et al., 2002, 2008; Sharkey and Faber, 2014; Small and Newman, 2001; Wilson, 1987). However, a single-generation approach may underestimate the full scope of how and when neighborhood context matters for inequality. Measurements of neighborhood conditions across multiple generations may more properly account for how neighborhoods shape inequality - at once expanding understandings of their lasting consequences and reorienting discussions about their relation to individual-level family background effects on wellbeing (Blau, 1960; Entwisle, 2007; Sharkey, 2008).

This paper builds on emergent research that examines the associations between parents' and children's multigenerational exposure to childhood neighborhood poverty and children's childhood developmental outcomes (Sharkey, 2013, chapter 5; Sharkey and Elwert, 2011). However, this paper is the first to examine the relationship between successive generations of exposure to childhood neighborhood disadvantage and children's adult neighborhood context. In doing so, we illuminate a more complete, multigenerational perspective of how neighborhoods transmit and maintain inequality.

Scholars studying stratification have recently begun to consider the lasting effects of individual-level characteristics on inequality across time (DiPrete and Eirich, 2006; Mare, 2011). Similarly, neighborhood researchers have also begun to consider the cumulative fashion in which 
exposure to deleterious neighborhood conditions may affect well-being. For example, Sharkey $(2008,2013)$ finds persistence in neighborhood economic status from one generation to the next. Sharkey and Elwert (2011) find that neighborhood poverty in childhood experienced over multiple generations is associated with children's cognitive reading and math assessment scores. Moreover, Chetty and colleagues (2014, p. 1554) state that the variation in intergenerational mobility across areas within the U.S. has created a "collection of societies, some of which are 'lands of opportunity" with high rates of mobility across generations, and others in which few children escape poverty." The current paper builds on the nascent literature on multigenerational neighborhood processes by linking three generations worth of family history and asking whether exposure to childhood neighborhood disadvantage across two consecutive generations is associated with children's adult exposure to neighborhood disadvantage. Based on previous research in this area (Sharkey, 2008, 2013; Sharkey and Elwert, 2011), we hypothesize that multigenerational exposure to neighborhood disadvantage will be positively associated with neighborhood disadvantage in successive generations.

This paper advances theory by illustrating how spatial inequality is reproduced across generations. Examining the degree of change in the spatial mobility structure may amplify scholars' understanding of the strength of neighborhoods in maintaining individual-level inequality. This paper makes four key contributions to a multigenerational perspective on spatial mobility. First, we examine truly inter-generational processes of neighborhood attainment by using children's adult neighborhoods as the outcome. To do so, we analyze unique data from the restricted tract-level National Longitudinal Survey of Youth 1979 cohort (NLSY79) and from the Child and Young Adult cohort (NLSY:CYA). These temporally ordered and linked data bridge three generations of the family and offer a rare opportunity to examine neighborhoods from a multigenerational perspective. Second, we build on existing research by utilizing a comprehensive list of variables to 
define neighborhood conditions rather than relying on neighborhood poverty or income alone. Third, we incorporate subjective measures of neighborhood conditions that are likely to more accurately represent individuals' true neighborhood context, as compared to government-defined administrative units such as Census tracts. Fourth, we contribute to the multigenerational neighborhood literature by controlling for unobserved confounders nested in the grandparent generation. We run cousin fixed effects models to reduce bias that stems from unobserved confounders such as grandparents' exposure to segregated schools and segregated neighborhoods prior to Brown v. Board of Education (1954) and the passage of the Fair Housing Act (FHA in 1968), respectively.

\section{Theoretical Background}

Residential context is associated with individuals' outcomes across the life course both directly and indirectly through various mechanisms, including access to high achieving schools and economic opportunities, exposure to environmental hazards, and contact with violence (Sampson et al., 2002; Sharkey and Faber, 2014; Small and Newman, 2001). In sociology, mobility studies have for decades described patterns of intragenerational trajectories of upward and downward advancement in social and economic status at the individual-level (Blau and Duncan, 1967; Bowles and Gintis, 2002; Jencks et al., 1972; Lipset and Zetterberg, 1959; Sewell and Hauser, 1975; Solon, 1992). At the neighborhood-level, scholars have also explored intragenerational mobility, finding that neighborhood conditions are often quite similar across time (Timberlake, 2007, 2009a, 2009b). Exits from disadvantaged neighborhoods are somewhat common, but are also often followed by reentry across the life course (Quillian, 2003). Black and Latino individuals, in particular, are not only more likely to live in hazardous environments, but are also unlikely to escape disadvantaged 
neighborhoods (Crowder and Downey, 2010; South and Crowder, 1997; Wilson, 1987). We seek to better align U.S. based neighborhood research with the growing international literature that examines social mobility through a multigenerational lens (Chan and Boliver, 2013; Hällsten, 2014; Hertel and Groh-Samberg, 2014; Jæger, 2012; Mare, 2011; Pfeffer, 2014; Pfeffer and Killewald, 2018, 2019; Roksa and Potter, 2011; Solon, 2014; Song, 2016; Song and Mare, 2015, 2019; Song et al., 2015; Zeng and Xie, 2014). By doing so, we hope to improve theoretical understandings of the role played by neighborhoods in shaping inequality both in the U.S. and abroad.

\subsection{Multigenerational Neighborhood Exposure}

While income, levels of education, and occupational status all influence patterns of neighborhood selection and geographic mobility, the persistence of ecological conditions is not solely attributable to variation in individual-level processes. Generations of racist housing legislation, redlining, and other structural constraints have produced the segregated residential landscape present today (Logan et al., 2004; Massey and Denton, 1993). The historical legacy of U.S. policies has created an uneven distribution of educational resources and economic opportunities that sustain the spatially unequal distribution of life chances (Jargowsky, 1997; Sampson, 2012). ${ }^{2}$ A robust and emergent literature is beginning to document segregation levels outside of the U.S. as well (Andersson et al., 2018; McAvay and Safi, 2018; Quillian and Lagrange, 2016; Tammaru et al., 2020). Although the levels and sources of segregation are different abroad, exposure to disadvantaged

${ }^{2}$ Despite the passage of the FHA and greater economic opportunity for some Black and Latino individuals, discrimination has maintained racial inequality in neighborhood environments and is one of the main drivers of multigenerational exposure to neighborhood disadvantage (Massey and Denton, 1993). Audit studies have confirmed the continued prevalence of racial and ethnic discrimination in housing (Turner et al., 2002; Yinger, 1995). This has had the effect of keeping many Black and Latino residents out of socioeconomically advantaged neighborhoods, even when they can afford homes in those areas (Reardon et al., 2015). 
neighborhoods may have similar detrimental impacts (Andersson and Malmberg, 2015; Andersson and Subramanian, 2006; Brännström, 2008; Goux and Maurin, 2007; Kauppinen, 2007).

Beyond structural barriers, place stratification theory holds that mobility restrictions contribute to the segregation that exists in the U.S. today. For instance, an extensive literature documents the way that affluent residents maintain an advantaged position in the "hierarchy of places” (Logan, 1978) by marshalling institutional and informal mechanisms to exclude undesirable residents from their neighborhoods. Real estate agents, banks, insurance companies, appraisers, housing developers, and government policies have historically worked in concert to exclude Black and Latino individuals from majority-white and more socioeconomically advantaged neighborhoods (Dreier et al., 2001; Green et al., 1998; Korver-Glenn, 2021; Massey and Denton, 1993; Yinger, 1995)..$^{3}$

Choice theory, in contrast, suggests that racial and ethnic groups' decisions lead to the maintenance of a stratified residential landscape. Cognizant of the continuance of segregated cities after the passage of the FHA and other Civil Rights Era legislation, scholars posit that whites' beliefs about living alongside Black neighbors has taken the place of overt acts of collective racism to undergird the stability of racial and ethnic inequality and segregation in the U.S. (Cutler et al., 1999). Continued segregation patterns, under choice theory, are partly a function of residential preferences and the fact that Blacks are often the least preferred neighbors and are therefore often segregated in pockets of poverty and disadvantage (Bobo and Zubrinsky, 1996; Charles, 2001). From this

\footnotetext{
${ }^{3}$ Research documents that poor families often make unplanned housing decisions under strained and evolving conditions related to employment, criminal records, immigration status, and eviction (DeLuca and Jang-Trettien, 2020; DeLuca et al., 2019), all of which further constrain their housing options. Unregulated home transfers outside of the mortgage market in Black neighborhoods may also place buyers in vulnerable positions, further exacerbating racial inequalities in housing (Jang-Trettien, 2021).
} 
perspective, the ultimate consequence of individual residential preferences and choices made mostly by white families is severe neighborhood segregation (van de Rijt et al., 2009; Schelling, 1971).

Cultural mechanisms may contribute to the reproduction of neighborhood conditions across generations as well. Because specific neighborhoods often encapsulate individuals' set of social and kinship ties, continuity in residential contexts may develop (Elder et al., 1996; Fried, 1982; Gerson et al., 1977; Mulligan, 1997, 1992). Social and psychological bonds may lead to persistence in neighborhoods through traditions and shared experiences. Children may also develop perceptions or a mindset of what types of neighborhoods are suitable, desirable, or even possible given the neighborhoods they are exposed to in their immediate and extended families. In disadvantaged neighborhoods, experiences of personal and economic adversity may strengthen bonds between community members because residents must lean on each other for social, emotional, and financial support. The bonds forged through hardship may even contribute to the development of strong preferences for co-ethnic neighbors in disadvantaged contexts (Charles, 2001). Together, these models suggest that structural factors such as discriminatory housing covenants and individual preferences or cultural mechanisms combine to maintain neighborhood segregation across multiple generations.

Neighborhood immurement may also help explain the reproduction of individual-level poverty across generations. ${ }^{4}$ That is, consistent exposure to contexts with a dearth of economic opportunities, rampant discrimination in housing, social disorganization, and intense policing across generations may constrain well-being for those who are in direct contact with these conditions in

\footnotetext{
${ }^{4}$ This paper aligns with studies that treat neighborhood-level and individual-level socioeconomic conditions as complementary social forces and provides a more comprehensive understanding of the processes that produce inequality in income, education, health, and other markers of well-being (Entwisle, 2007; Klebanov et al., 1997; Massey, 2007; Sharkey, 2008; Wilson, 1991).
} 
addition to progeny indirectly exposed in successive generations. This process is encapsulated in the concept of social isolation. ${ }^{5}$ For social isolation to have a deep and lasting impact on well-being, however, individuals must experience extended spells of exposure to disadvantaged neighborhoods. A multigenerational approach allows for an investigation of whether sustained structural disadvantage produces deleterious consequences for well-being, such as those that scholars theorize flow through social isolation. Although we do not directly explore mechanisms of neighborhood effects such as social isolation, a multigenerational analysis creates a lens to view such mechanisms that likely affect well-being.

Building on Sharkey's (2013) idea of being “stuck in place," we argue that neighborhood context may be preserved across multiple generations through indirect and direct means. A robust literature demonstrates that childhood neighborhood conditions are associated with an array of outcomes in childhood (Alvarado, 2016a, 2016b; Sampson et al., 2008; Wodtke and Parbst, 2017; Wodtke et al., 2011, 2016) and in adulthood (Alvarado, 2018, 2019; Chetty et al., 2016; KravitzWirtz, 2016; Vartanian and Buck, 2005). The implication of this literature is that as individuals move through the life course, they become conduits through which the impacts of the spatial opportunity structure in one generation are transmitted onto the next (Galster and Sharkey, 2017).

Conceptualizing neighborhoods multigenerationally may therefore expose the cumulative fashion in which they operate.

\subsection{Consistent Exposure to Disadvantaged Neighborhoods}

\footnotetext{
${ }^{5}$ Social isolation describes a detachment from mainstream norms of behavior, value systems, and economic opportunity which are a consequence of exposure, especially prolonged exposure, to neighborhoods where joblessness and idleness are common, affecting the structure of everyday life (Wilson, 1996).
} 
Place matters, but its significance may hinge on the amount of time spent in an environment. Although much of the past research on neighborhoods has considered short-term intervals or "snapshots" of residency, neighborhood scholars have increasingly been able to use longitudinal data to capture a more holistic view of the contexts in which children grow up. As a result, scholars consistently find that duration of exposure may underlie associations between neighborhood conditions and well-being (Alvarado, 2018; Chetty et al., 2016; Harding, 2003; Sharkey and Elwert, 2011; Vartanian and Houser, 2010; Wodtke, 2013). Given that consistent exposure during one's childhood is associated with well-being, it stands to reason that consistent exposure over successive generations does so as well. Nevertheless, the bulk of this literature continues to focus solely on neighborhood associations within a single generation without accounting for exposure in previous ones.

Sharkey (2008) moves the literature toward a dynamic view of neighborhood disadvantage and inequality that accounts for mobility across generations. He reveals remarkable continuity in neighborhood economic status from one generation to the next by examining children's adult neighborhood income as a function of parent's adult neighborhood income. One could also think of this as being an intragenerational story of mobility within the child's own life, given that the parents' adult neighborhood is essentially the neighborhood conditions where the child grew up. In contrast, Sharkey and Elwert (2011) examine two consecutive generations of exposure to childhood neighborhood poverty and children's childhood cognitive ability. In contrast to Sharkey's (2008) study, Sharkey and Elwert (2011) do indeed measure neighborhood context across two generations in their treatment variable. However, given that their outcome is children's childhood cognitive ability, they do not connect these multigenerational processes of neighborhood exposure to neighborhood attainment across generations. Sharkey's (2013, chapter 4) analysis uses Panel Study 
of Income Dynamics (PSID) data on two successive generations of family members. He finds that parents who were raised in poor neighborhoods during the Civil Rights Era are very likely to also raise their own children in poor neighborhoods today (Sharkey, 2013). ${ }^{6}$ Building on these foundational works, we seek to assess the role of multigenerational exposure in the process of neighborhood attainment.

\section{Data}

We analyze 35 years of federally restricted tract-level NLSY data between $1979-2014$ and across 27 survey waves on encrypted machines at the Bureau of Labor Statistics' (BLS) headquarters in Washington, DC. We link NLSY79 female respondents to their NLSY:CYA children to capture kinship lines. As Figure 1 depicts, we consider the parents of the NLSY79 respondents to be the first generation (subsequently referred to as G1), the NLSY79 respondents the second generation (G2, "child”), and the NLSY:CYA respondents the third (G3, "grandchild").

[Figure 1 about here]

\footnotetext{
${ }^{6}$ Informed by Sharkey (2013), we contribute to the literature on multigenerational neighborhood effects in several ways. For example, we use children's adult neighborhoods as the outcome. Sharkey's (2013) approach that uses children's childhood neighborhoods as the outcome in chapter 4 may be understood as a single-generation study if one is to consider the fact children's childhood neighborhoods are also parents' adult neighborhoods. A second contribution is that we go beyond neighborhood poverty by using a multidimensional composite. This aligns with earlier studies that adopt a multidimensional understanding of neighborhood disadvantage (Alvarado, 2016a; Crowder and South, 2003, 2011; Harding, 2009; Massey et al., 2018; Sharkey, 2013; Shih et al., 2012; Wodtke et al., 2011). We claim only that we are the first to do this in the literature on multigenerational neighborhood effects Sharkey (2013, chapter 5) and Sharkey and Elwert (2011) use multigenerational neighborhood poverty as their predictor. Third, we incorporate subjective measures of neighborhood conditions. Fourth, we control for unobserved confounders nested in the grandparent generation.
} 
The NLSY79 is an ongoing, nationally representative, multi-stage clustered sample of 12,686 young men and women who were $14-22$ years old when they were first surveyed in 1979 . We analyze NLSY79 females who had children by 2014 because only females are linked to their biological children in the NLSY:CYA. Fertility has increased over time, augmenting the number of mothers in more recent waves. These women were ages 49 - 58 in 2014 . The NLSY79 data provide us with information on their parents' household characteristics (G1), their own (G2) childhood neighborhood locations, and their children's (G3) childhood neighborhood locations. All tract locations are tied to G2, the NLSY79 female respondents.

The NLSY:CYA is comprised of all the biological children born to a nationally representative sample of women aged 21 - 29 as of January 1, 1986. These data provide us with information on the neighborhood attainment in adulthood of G3. The eldest of these children were born in 1970 and were 44 years old in 2014. Starting in 1986, the BLS collected data every two years for all youth that were born (or would be born) to female NLSY79 respondents. Some children were born to young and socioeconomically disadvantaged mothers. Over time, the sample of mothers becomes increasingly representative of mothers across the full range of childbearing years, thereby reducing the overrepresentation of mothers who had children at young ages. Moreover, we address any bias stemming from mothers' young childbearing by controlling for grandparents' household characteristics (Geronimus et al., 1994; Turley, 2003). Many female respondents are sisters in the NLSY79 sample (G2), allowing for the identification of cousins in the NLSY:CYA sample (G3). Most of these cousins have one aunt, but some have multiple aunts (up to 4). We leverage this feature of the data set by including children of NLSY79 sisters in cousin fixed effects (FE) models.

The two linked NLSY79 and NLSY:CYA cohorts are ideally suited to advance the neighborhood literature through a multigenerational lens. However, our study must make certain 
necessary restrictions to the sample to maintain kinship lines. Therefore, G3 children are included in the analysis only if they meet certain non-mutually exclusive criteria. First, G3 respondents must belong to the approximately 3,550 G2 mothers who were between $14-18$ years old in 1979 so we can gather data for G1's household characteristics and G2's childhood neighborhood conditions.

Second, to measure G3's childhood neighborhood exposure, data for census tracts must be available for G2 respondents for at least one year before G3 respondents turned 19. Third, G3 respondents must belong to mothers who had their first child by 1995 so that we can measure their adult neighborhood attainment (age 19+). Fourth, household socioeconomic data and tract location data must be available for G2 in childhood for at least one year before they turned 19 between 1979 and 1983. Fifth, the cousin fixed effects model further restricts the analytical sample to G3 respondents who have at least one cousin by 2014 with adult neighborhood data and to those who had withinfamily variation in intergenerational childhood neighborhood exposure.

The final analytical sample for the cousin FE models includes approximately 2,400 G3 cousins. No G3 respondents are dropped due to missing control variables because we imputed for any missing G2 childhood household and neighborhood characteristics. Our results are based on children of NLSY79 females who were 14 - 18 in 1979, which is representative of a cross-section of the U.S. population in 1979, who had cousins. Our sample is therefore not representative of the current U.S. population due to demographic changes since the late 1970s, variation in family formation among NLSY79 sisters, and the stated exclusion criteria. There is no data set currently available that yields multigenerational neighborhood estimates that are generalizable to the nation.

\subsection{Multigenerational Neighborhood Disadvantage}


Linked data from the NLSY79 and the NLSY:CYA facilitate a dynamic long-term analysis across three generations. First, we use the neighborhoods of G2 when they were under the age of 19 $(1979$ - 1983). Second, we use the neighborhoods of G3 when they were under age 19. Third, we use subjective assessments of the neighborhood conditions of G3 when they were over the age of 18 as our outcome. Following previous research, we average neighborhood conditions across time for respondents to reduce measurement error (Aaronson, 1998; Sharkey and Elwert, 2011; Vartanian and Buck, 2005).

We create a composite scale of tract-level disadvantage to capture the multidimensionality of neighborhood context in each wave of the survey for G2 between ages $14-18$ and for G3 between ages $0-18$. We use the following seven standardized variables: (1) percent of residents at or below $100 \%$ of the poverty threshold as defined by the U.S. Census Bureau; (2) percent jobless; (3) percent not in the labor force; (4) percent with at least a Bachelor's degree, reverse coded; (5) percent managers and professionals, reverse coded; (6) median income, reverse coded; and (7) median housing value, reverse coded. The Cronbach's $\alpha$ is 0.88 . We calculate the average of this scale score across the childhood waves of G2 and G3. Then, we assign G2 and G3 quintile scores (1 is least disadvantaged; 5 is most disadvantaged) to capture the mean exposure to neighborhood disadvantage during childhood. Next, we create a dichotomous variable (where 0 represents quintiles $1-3 ; 1$ quintiles 4 or 5) to define being exposed to neighborhood disadvantage during childhood for both G2 and G3.

We follow Sharkey (2013) and use a four-category factor variable to measure exposure to neighborhood disadvantage based on the two dichotomous variables described above: (1) neither G2 nor G3 were exposed in childhood - the reference category; (2) only G2 was exposed in childhood; (3) only G3 was exposed in childhood; and (4) both G2 and G3 were exposed in 
childhood. The fourth category, which indicates multigenerational exposure to neighborhood disadvantage in childhood, is our primary category of interest. In our discussion of results, we refer to four types of family trajectories that relate to our four-category factor variable: (1) neither; (2) ascending; (3) descending; and (4) stuck-in-place. Figure 2 schematically illustrates each of these family trajectories. An ascending family is one where G2 was exposed to childhood neighborhood disadvantage, but G3 was not. A descending family is one where G2 was situated in an advantaged neighborhood context during childhood, but G3 was exposed to a disadvantaged neighborhood in childhood. These patterns represent an upwardly mobile and a downwardly mobile family lineage, respectively. Our focus is on the scenario of multigenerational exposure to disadvantaged residential context in childhood for both G2 and G3. This is what we refer to as rigid family neighborhood contextual mobility, conforming to the idea of families being "stuck in place" (Sharkey, 2013).

[Figure 2 about here]

\subsection{Generation 3 (Grandchild) Adult Exposure}

Our outcome of interest is the mean exposure to subjective adult (ages 19-44)

neighborhood disadvantage for G3. That is, we use an average value of G3's per-wave scale scores in adulthood and then dichotomized this value to either be in quintiles $1-3$ or in quintiles $4-5$. The approach we take is like that outlined above for G2 and G3 childhood exposure. That is, we capture the average exposure to neighborhood disadvantage across G3's adulthood. However, we use a subjective assessment of neighborhood conditions and different variables as components of the scale. The reason for these deviations is that the BLS only provides Census tract geocodes for the NLSY79 sample, not the NLSY:CYA. Therefore, we do not know the tracts where G3 lived as 
adults after likely leaving their mothers' (G2) homes. The BLS asks these respondents subjective questions about their neighborhoods and the G3 adult neighborhood disadvantage scale is a composite of NLSY:CYA respondents' concerns that the following conditions are a problem in the neighborhood where they reside as adults in each wave: (1) people do not respect rules/laws; (2) crime and violence; (3) abandoned/run-down buildings; (4) parents do not supervise their children; (5) people do not care/keep to themselves; and (6) people cannot find jobs. The Cronbach's $\alpha$ is .81. This scale does not exactly match the components of the scale created for the childhood neighborhoods of G2 and G3, but it does parallel the concept of underlying multidimensional neighborhood socioeconomic conditions. Previous scholars have also contended that subjective neighborhood assessments are equally as important to urban theory as objective assessments (Lee et al., 1994; Logan and Collver, 1983).

\subsection{Control Variables}

We control for G2's childhood household conditions - these also represent G1's adult characteristics - which may predict the neighborhoods where G2 grew up as well as the neighborhoods where G3 grew up (via the association between G2's childhood neighborhood and G2's adult educational and socioeconomic attainment). These data stem from 5 survey waves between the years 1979 and 1983, when the NLSY79 female respondents were under age 19. We follow previous research and average our control variables across time to reduce measurement error (Aaronson, 1998; Sharkey and Elwert, 2011; Vartanian and Buck, 2005). Table 1 includes means and standard deviations for the observed controls we use. The features of G2's childhood household characteristics that we control for include household structure, education, employment, income, and poverty - all of which pertain to the adult characteristics of G1. We do not control for G2's adult 
household characteristics to avoid overcontrolling that may suppress the association for multigenerational exposure to neighborhood disadvantage. ${ }^{7}$

[Table 1 about here]

\section{Methods}

We extend previous neighborhood studies that have used sibling fixed effects (Aaronson, 1998; Alvarado, 2018; Plotnick and Hoffman, 1999; Vartanian and Buck, 2005) by using cousin fixed effects to control for unobserved confounders nested in the grandparent generation. The primary advantage of the cousin FE model is the ability to control for omitted grandparental experiences (e.g., grandparents' school segregation, housing segregation, and genes) that might be correlated with neighborhood context in a family-specific error term (Aaronson, 1998). Among the weaknesses are that FE models cannot account for unobserved grandparental factors that vary across G3 respondents' and their G2 mothers (e.g., differences in grandparents' psychological and emotional states while they were rearing G2 sisters or other less-measurable differences in household characteristics). ${ }^{8}$ Variation in neighborhood profiles between G2 sisters ages $14-18$ in 1979 stems from measurements from intervening years after older sisters had turned 19 during which time

\footnotetext{
${ }^{7}$ G2's observed adult household characteristics influence the selection of G3's childhood neighborhood of residence, placing G2's adult household characteristics on the causal pathway between G2's childhood neighborhood and the outcome (G3's adult neighborhood). Controlling for G2's adult household characteristics would create an endogeneity problem because it would "control away" a portion of the association between G2's childhood neighborhood and G3's adult neighborhood, ultimately producing bias (for a discussion about the pitfalls of overcontrolling, see Sharkey and Elwert, 2011).

${ }^{8}$ Any psychological or emotional dispositions that are genetically rooted should be at least partially addressed in the cousin FE models.
} 
parents may have either moved or the neighborhoods may have changed around families that did not move. Ultimately, however, we use variation from both G2 and G3 generations in our analyses.

Our models aim to estimate associations between neighborhood conditions across generations; we do not estimate causal effects. ${ }^{9}$ Our study begins with descriptive associations focused on multigenerational exposure to neighborhood disadvantage. We include all of G2's observed childhood characteristics as controls in multivariable pooled logistic models. These estimates may be biased due to the correlation between neighborhood conditions and unobserved family characteristics passed down from grandparents in G1. We then progressively attempt to rule out alternative explanations through the use of cousin FE models which account for unobserved G1 characteristics. We follow Aaronson (1998) and run a fixed effects linear probability model that addresses unobserved "hidden" confounding. The FE model capitalizes on variation in intergenerational neighborhood conditions between cousins that arises from differing family trajectories between G2 and their children in G3. We run LPM cousin FE models because of concerns regarding the incidental parameters problem that arises when using fixed effects in the presence of a binary outcome/binary treatment (Chamberlain, 1980; Miller et al., 2018). We cluster our standard errors to the highest level of aggregation, G1 (Cameron and Miller, 2015; Cameron et al., 2011; Pepper, 2002). The cousin FE model is our preferred model. ${ }^{10}$

\footnotetext{
${ }^{9} \mathrm{We}$ argue that inequality is rooted, at least in part, in intergenerational processes that are unobserved. Therefore, the cousin FE model is our primary model because it will minimize spuriousness in our estimates by controlling for shared confounders that are passed down from G1 to G2 and then onto cousins in G3. Such confounders could include genes, pre-Fair Housing Act segregation, and discrimination in housing in addition to pre-Brown v. Board segregation in schooling - all of which may have affected G1's educational outcomes, economic outcomes, and neighborhood selection. These unobserved confounders could have lasting impacts on social and spatial mobility across generations.

${ }^{10}$ In the FE model, we compare full biological cousins based on the ID of grandparents in G1. The analytical sample only consists of maternal cousin groups - therefore, the cousin FE model only controls for unobserved confounders for the maternal side of the family. The G3 respondents may either be the only-child of G2 mothers (who have at least one sister) or have several siblings.
} 
Following Allison (2009), the multivariable linear probability cousin FE model that predicts that $Y_{i j}=1$ (i.e., the $\mathrm{G} 3$ respondent ever experiences neighborhood disadvantage in adulthood) takes the following form:

$$
Y_{i j}=\beta_{0}+\beta_{l} N D_{l, i j}+\beta_{m} G 1 \text { Controls }_{m, i j}+\alpha_{j}+\varepsilon_{i j}
$$

where the indexes $i$ and $j$ refer to the individual $i$ in cousin group $j, N D_{l, i j}$ is a four-category factor variable for intergenerational exposure to childhood neighborhood disadvantage, and

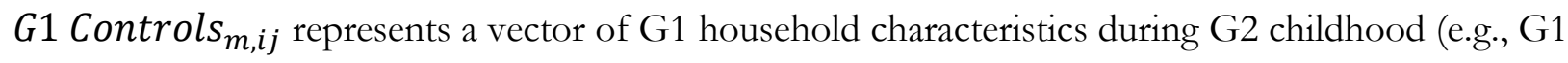
poverty, income, and education that are averaged across G2 childhood), where $\alpha_{j}$ is the fixed effect for cousin group $j$ that represents the combined effect on the outcome of all unobserved variables that are constant among cousins, and where $\varepsilon_{i j}$ is the residual which represents purely random variation for each cousin.

\section{Results}

Figure 3 renders the percent of G3 respondents who are exposed to neighborhood disadvantage in adulthood (i.e., have a mean scale score across adulthood that falls in either quintiles 4 or 5) by family lineage of exposure to childhood neighborhood disadvantage. The results are as we would expect. Moving from the family lineage where neither G2 nor G3 respondents grew up in disadvantaged neighborhoods to the family lineage where both did, the percent of G3 respondents living in disadvantaged neighborhoods in adulthood increases in a linear fashion. These results suggest that belonging to a family where two consecutive generations grew up amidst socioeconomic 
neighborhood disadvantage increases the likelihood of bequeathing that legacy of contextual disadvantage to successive generations, especially relative to families where neither generation was exposed. These results also speak to the rigidity of the residential mobility structure in the U.S. and cohere to the idea that families may indeed be "stuck in place" (Sharkey, 2013). These descriptive findings hint at the importance of a multigenerational perspective when studying neighborhood associations and provide the foundation for the remainder of our analyses.

[Figure 3 about here]

Figure 4 presents the predicted probabilities of G3 respondents living in a disadvantaged neighborhood in adulthood drawn from the unadjusted logistic regression model included in Appendix A. The graph demonstrates that the probability of G3 respondents experiencing adult neighborhood disadvantage increases as a function of exposure to neighborhood disadvantage across their family lineage. When neither G2 nor G3 is exposed to childhood neighborhood disadvantage, the probability of G3's adult exposure is approximately 26 percent. This probability grows to 33 percent when only G2 is exposed, grows to 46 percent when only G3 is exposed, and peaks at 53 percent when both G2 and G3 respondents are exposed to disadvantaged neighborhood conditions in childhood. These results align with expectations about the cumulative effects of social isolation and the rigidity of the spatial mobility system of stratification in the U.S. (Sharkey, 2013; Wilson, 1987).

[Figure 4 about here] 


\subsection{Logistic Regression}

Table 2 summarizes the coefficients for the logistic regression model that includes G2's childhood household characteristics as controls. The adjusted results demonstrate that for ascending families, the odds of G3 living in a disadvantaged neighborhood in adulthood increase by 36 percent compared to families without any childhood exposure in either G2 or G3 ( $\left.e^{[0.31]}=1.36\right)$, net of G2's childhood household characteristics. Next, for descending families, the results suggest that the odds of G3 living in a disadvantaged neighborhood in adulthood increase by 114 percent $\left(e^{[0.71]}=2.14\right)$ compared to families without any childhood exposure in either G2 or G3, net of G2's childhood household characteristics. Finally, for our focal families that are stuck in place, the adjusted results suggest that the odds of G3 living in a disadvantaged neighborhood in adulthood increases by 164 percent $\left(e^{[0.97]}=2.64\right)$ compared to families without G2 or G3 childhood exposure, net of G2's childhood household characteristics. However, these results may be spurious to unobserved confounders that are nested in the lived experiences of G1.

[Table 2 about here]

\subsection{Fixed Effects Linear Probability Model}

We now discuss results from cousin fixed effects linear probability models that adjust for unobserved confounders nested in G1. These results represent our most robust estimates of the association between multigenerational exposure to childhood neighborhood disadvantage and G3's adult exposure to neighborhood disadvantage. Table 3 suggests that for ascending families, childhood exposure in G2 increases the probability of exposure by 13 percentage points, net of G2's childhood household characteristics and net of unobserved time-invariant characteristics of 
G1. Next, we turn to stuck-in-place families. These results suggest that childhood exposure in successive generations increases the probability of adult exposure in G3 by 18 percentage points, net of G2's childhood household characteristics and net of unobserved time-invariant characteristics of G1. The results indicate that families who remain stuck in disadvantaged neighborhoods across two generations are likely to do so again, net of observed and unobserved confounders that cascade down from the grandparent generation. These results reaffirm Sharkey's (2013) findings that families who reside in disadvantaged neighborhoods are likely to be stuck in place for several generations. ${ }^{11}$

[Table 3 about here]

These results demonstrate several important findings. First, across successive models, observed and unobserved confounders explain much of the unadjusted zero-order associations. Second, we must seriously consider the qualitative differences between families on divergent residential mobility trajectories and, importantly, the role played by unobserved factors when

\footnotetext{
${ }^{11}$ Table 3 demonstrates that there is no statistically significant association between only G3 childhood exposure and G3 adult neighborhood disadvantage after controlling for unobserved confounders that descend from the grandparent generation. This finding contrasts with Sharkey's (2008) finding of a positive association between children's childhood neighborhood income and their adult neighborhood income. However, Sharkey's (2008) finding did not account for unobserved confounders. Further, it is important to note that these G2 respondents in descending families have been knocked off the main diagonal of the intergenerational residential mobility structure. Possible reasons for families to be on such downward neighborhood trajectories include negative selection that stems from unobserved important events originating in the prior generation such as discrimination, depression, or other influential shocks that affected G2 while they were growing up vis-à-vis G1 and persisted into adulthood. These events may explain away the statistically significant positive associations between G3's own childhood neighborhood disadvantage and their adult neighborhood disadvantage that were present in earlier non-cousin FE models. The implication is that a multigenerational account of neighborhood associations reorients theory of individual-level events that have consequences for well-being. That is, neighborhood associations may not only manifest in their relationship to well-being, as is clearly demonstrated in the literature (Sharkey \& Faber, 2014), but may also be influenced by well-being in previous generations.
} 
examining the outcomes of residential mobility across generations. Third, the most robust model presented in Table 3 yields a positive association for ascending families and stuck-in-place families.

Finally, we would be remiss if we did not point out the potential positive selection on unobserved traits of ascending G2 respondents. These include motivation, ambition, or grit to succeed which may have been the catalyst that allowed them to escape the disadvantaged neighborhoods of their youth. Nevertheless, these factors may not have been sufficient to completely erase the lingering positive association between the neighborhood disadvantage of their childhood and the adult neighborhood disadvantage of their children.

\subsection{Predicted Probabilities}

Figure 5 renders the predicted probability of G3 living in a disadvantaged neighborhood in adulthood as a function of exposure to childhood neighborhood disadvantage across successive generations of the family. These probabilities, which are based on the cousin FE results from Table 3, suggest that the probability of G3 living in a disadvantaged neighborhood in adulthood is 33 percent if neither G2 nor G3 lived in a disadvantaged neighborhood in childhood, 45 percent if only G2 was exposed, 33 percent if only G3 was exposed (although the difference between G3's childhood exposure and neither generation exposure is not statistically significant), and 50 percent if childhood exposure occurred in both the G2 and in the G3 generations.

[Figure 5 about here]

\subsection{Alternative Definition of Neighborhood Disadvantage}


So far, we have operationalized neighborhood disadvantage as growing up in the top two quintiles of neighborhood disadvantage. An alternative experience is growing up in the top quintile of neighborhood disadvantage versus the bottom four quintiles. This more extreme level of exposure may yield stronger associations with G3's adult exposure. Here, we also redefine the outcome to indicate G3's adult exposure to the most extreme neighborhood disadvantage quintile versus the bottom four quintiles.

Table 4 summarizes results from logistic regression models that contrast growing up in the bottom four quintiles of neighborhood disadvantage with growing up in the top quintile. The zeroorder and adjusted results for this more extreme specification in Table 4 demonstrate positive associations that are stronger than those for the less extreme specification in Table 2 . This pattern of a larger total association aligns with the expectation of acute consequences due to exposure to the most extreme forms of neighborhood disadvantage. However, the coefficient for G2 only exposure is not statistically significant after including observed adjustments.

[Table 4 about here]

In Table 5, we summarize the results for the most extreme specification after adding adjustments for unobserved confounders nested in G1. These cousin FE models demonstrate that childhood exposure in G2 is positively associated with adult exposure in G3 and that successive generations of exposure is also positively associated with adult exposure in G3. Moreover, childhood exposure in G3 alone does not yield a statistically significant association with adult exposure in G3. These results align perfectly with the results from the less extreme specification for neighborhood disadvantage in Table 3. However, in contrast to our expectation, there is no 
discernable difference in the magnitude of the associations between the less and more extreme specifications of neighborhood disadvantage.

[Table 5 about here]

These results suggest that our substantive takeaways from our original specification of neighborhood disadvantage are reinforced by an alternative and more extreme specification of neighborhood disadvantage. That is, multigenerational exposure to childhood neighborhood disadvantage has a positive association with G3's adult exposure to neighborhood disadvantage. However, even though the total associations suggest stronger associations for the most extreme specification in Table 4, there is little support for the expectation that the most extreme specification of neighborhood disadvantage yields stronger associations after adjusting for unobserved confounders.

\subsection{Ever Exposed in Adulthood}

We now supplement the analysis with a specification of the outcome that identifies whether G3 respondents have ever been exposed to neighborhood disadvantage at any point in adulthood, rather than using mean exposure across adulthood as we have examined up to now. Table 6 summarizes the results for the zero order models (Models 1 and 4), models with observed adjustments (Models 2 and 5), and LPM models with observed adjustments and cousin FE models (Models 3 and 6). As definitions of neighborhood disadvantage exposure in childhood, we use both the original specification (Models $1-3$ ) and the most extreme specifications (Models $4-6$ ) of childhood neighborhood disadvantage exposure in G2 and G3. 
[Table 6 about here]

The findings support the main results in Tables $2-5$. That is, when using the supplemental definition of the outcome, we still find that two consecutive generations of childhood exposure to neighborhood disadvantage is positively associated with G3 ever being exposed to adult neighborhood disadvantage. The results from the cousin FE models in Table 6 suggest that being stuck-in-place increases the probability of G3 adult exposure by 7 percentage points in the original specification of childhood neighborhood disadvantage and by 30 percentage points in the supplemental specification of childhood neighborhood disadvantage, net of G2's childhood household characteristics and net of unobserved time-invariant characteristics of G1. These findings, while based on a more limited notion of G3's adult neighborhood disadvantage exposure, further support the main conclusions.

\section{Conclusion}

Recent research finds that neighborhood conditions persist over time and across generations, creating legacies of disadvantage and reproducing poverty as families become "stuck in place" (Sharkey 2008; 2013). The continuity of neighborhood conditions compels scholars to consider the interconnectedness between spatial inequalities in current generations with those of the past. Moreover, linking spatial and social mobility across time increases the salience of neighborhoods as core features of stratification that, along with family socioeconomic status and other individual-level characteristics, lie at the foundation of inequality in the United States. This paper builds on recent multigenerational neighborhoods research by extending the measurement of 
neighborhood conditions across multiple generations, using a more comprehensive definition of neighborhood disadvantage, incorporating subjective measures of neighborhood conditions into our models, and by controlling for unobserved confounders nested in the grandparent generation. We also introduce a new data set to the literature.

Using restricted tract-level data from the National Longitudinal Survey of Youth (NLSY79 and NLSY:CYA), the core finding of this paper is that families in which G2 and G3 are both exposed to disadvantaged neighborhoods in childhood are likely to reproduce that neighborhood disadvantage in G3's adulthood. The results answer our research question in the affirmative. Theoretically, structural discrimination and segregation in previous generations may matter for residential mobility trajectories of subsequent generations through mechanisms such as childhood physiological, social, and academic outcomes which in turn are associated with adult economic and health outcomes. Additionally, cultural mechanisms such as traditions and shared experiences and bonds with friends and family members may tie individuals to neighborhoods over time. In disadvantaged contexts, social and kinship bonds forged through hardship in the neighborhoods of immediate and extended family members may contribute to the development of perceptions about what types of neighborhoods are suitable, desirable, or even possible - all of which may reproduce neighborhood contexts across generations. Individual preferences and choices also play a role, and overt racism and discrimination post-FHA contributes to the production and persistence of intergenerational inequality across racial and ethnic groups in the contemporary U.S.

This is the first paper to illuminate that, even net of unobserved experiences of grandparents and genes, neighborhoods can transcend generations. This finding adds credence to the argument regarding the need for scholars to examine the intergenerational transmission of inequality (Mare, 2011; Pfeffer, 2014; Pfeffer and Killewald, 2018, 2019; Song, 2016; Song and Mare, 2015, 2019; Song 
et al., 2015). Indeed, recent research from the Moving to Opportunity (MTO) study estimating the lasting consequences of duration of exposure to neighborhood context may understate the true magnitude of how neighborhoods impact well-being given that it focuses on single-generation exposure (Chetty et al., 2016).

Among descending families, the cousin FE results in Table 3 suggest that G3 childhood neighborhoods may not influence adult neighborhoods once one controls for unobserved confounders that are nested in G1. This finding may seem surprising, but it is actually aligned with recent studies that analyze the relationship between childhood neighborhoods and income, employment, educational attainment, and incarceration in adulthood within a single generation (e.g., Alvarado, 2018, 2020; Chetty et al., 2018), if G3 childhood exposure is on the causal pathway from G1 unobserved characteristics to G3 adulthood exposure.

The statistically significant association for G2 childhood exposure in the cousin FE model in Table 3 is likely due to the fact that neighborhood disadvantage in the 1960s and 1970s (i.e., when G2 childhood exposure occurred [our analytical sample of NLSY79 female respondents were born between 1961 and 1965]) was more severe than in the 1980s and 1990s (i.e., when G3 childhood exposure occurred) because of the state and socially sanctioned racism and segregation prevalent in the 1960s and 1970s. Because of this less pernicious quality of neighborhood disadvantage in the 1980s and 1990s, G1 unobserved confounders may have been sufficient to completely explain away the association for G3 only childhood exposure in Table 3. For context, one must recall that (1) discrimination in housing was much higher prior to the passage of the FHA in 1968 (Sharkey, 2008; Turner et al., 2002; Yinger, 1995), (2) white-Black segregation declined in the 1980s and 1990s (Friedman, 2008), and (3) Blacks (especially nonpoor Blacks) experienced significant upgrades to the quality of their neighborhoods in the 1980s and 1990s as demonstrated through reductions in the 
percent of Black residents in mid-to-high poverty neighborhoods (Iceland and Hernandez, 2017; Sharkey, 2014). Taken together, these are signs that neighborhood disadvantage in the 1960s and 1970s (representative of G2 childhood exposure) was likely more severe than neighborhood disadvantage in the 1980s and 1990s, suggesting that G2 childhood exposure may have had a higher absolute association with G3 adult neighborhood exposure compared to G3 childhood exposure. G1 unobserved confounders may have explained away equally proportional amounts of the zeroorder associations for G2 and G3 childhood exposures, but the association for G2 could still be larger than the association for G3 because G2 childhood neighborhood disadvantage was occurring during a period of state and socially sanctioned segregation in all aspects of American life during the 1960s and 1970 s.

Overall, the findings of a statistically significant association for G2 childhood exposure and, most importantly, for multigenerational exposure support the argument for the necessary reorientation of neighborhoods as features of inequality that are intertwined with individual-level processes and that reflect salient events from previous generations (Sharkey, 2008, 2013). Instead of considering neighborhood associations as rivals to individual-level associations (e.g., parental income and education), it may be prudent for scholarship to consider how the two affect one another and intersect to reproduce inequality (Blau, 1960; Entwisle, 2007). Moreover, our findings align with recent research that has found intergenerational associations when examining the relationship between grandparent characteristics and their grandchildren's outcomes (Anderson et al., 2018).

Through cousin fixed effects, we make the contribution of controlling for unobserved confounders that are nested in G1 and cascade across successive generations that could bias estimates of neighborhoods. That is, families experiencing successive generations of exposure to neighborhood disadvantage may also suffer from associated disadvantage that is not captured by 
observed characteristics. For instance, these families may have suffered the injustices of de jure residential and school segregation in the housing market and in educational facilities that G1 encountered decades ago. These families may have also accumulated disadvantages that were the result of events and processes that interacted with being exposed to successive generations of neighborhood disadvantage such as political disenfranchisement, police brutality, discrimination in the labor market, and physical and mental health problems in previous generations (Sharkey, 2013).

Our analysis is not without limitations. For example, future scholars should incorporate measures from G1's childhood. We should also point out that we truncate the cousin FE sample to sisters from the NLSY79 who had any children and were between ages 14 - 18 in 1979. There may be some selection on who has children that could bias our cousin FE estimates. This paper also suffers from not having a complete picture of childhood neighborhood contexts for G2 or a complete picture of G3's adult neighborhoods. Moreover, we only have data for the household characteristics and the childhood neighborhood contexts for the mothers in G2. Further, there is no exogenous variation in neighborhood contexts in any generation.

We learn that multigenerational exposure to childhood neighborhood disadvantage is associated with neighborhood conditions across generations. The NLSY data allow us to rule out some competing explanations that cascade from the grandparent generation such as genes and exposure to segregated schools and neighborhoods in the middle of the $20^{\text {th }}$ century. But we cannot rule out other upstream competing explanations such as differences in G1's child rearing practices across G2 sisters and other unobserved household characteristics. Another consideration is that the current methods do not directly account for collider variable bias and conditioning on intervening mechanisms (Breen, 2018). Some of these concerns likely apply to our analysis. Alternative methods, such as marginal structural models (MSM), can address the issue of collider variable bias that might 
be introduced when controlling for G3 childhood neighborhood status (which is endogenous to G2 neighborhood status), but it is unclear whether MSMs are compatible with cousin FEs that have the advantage of addressing unobserved confounders in the G1 generation. The external validity of the conclusions may also be limited because of our exclusion criteria. Nevertheless, we know of no other existing panel data set that would allow us to increase the external validity of the conclusions while using a cousin FE framework.

This paper's theoretical reconceptualization of residential mobility moves research toward a view that encompasses multigenerational processes and aligns with international research that has found multigenerational associations with individual-level social mobility in Sweden (Hällsten, 2014) and Germany (Hertel and Groh-Samberg, 2014). Among the potential mechanisms for our findings on multigenerational exposure to neighborhood disadvantage that may apply on an international scale include consistent exposure to under-resourced schools and stagnant local labor markets.

Our results suggest that current neighborhood inequality is likely a function of multigenerational processes of exposure and inheritance. Based on our finding that neighborhood disadvantage is largely inherited from previous generations, and considering that neighborhoods are associated with various features of well-being (e.g., income, education, and health), mitigating inequality may rely even more heavily on altering the contexts in which children grow up than researchers and policy makers may currently appreciate. This paper contributes to scholarship that is beginning to expand our understanding of the crucial role of neighborhoods for reproducing poverty and its reverberation across generations. 


\section{REFERENCES}

Aaronson, D. (1998). Using Sibling Data to Estimate the Impact of Neighborhoods on Children's Educational Outcomes. J. Hum. Resour. 33, 915-946.

Allison, P.D. (2002). Missing Data (Thousand Oaks: Sage Publications).

Alvarado, S.E. (2016a). Delayed Disadvantage: Neighborhood Context and Child Development. Soc. Forces 94, 1847-1877.

Alvarado, S.E. (2016b). Neighborhood disadvantage and obesity across childhood and adolescence: Evidence from the NLSY children and young adults cohort (1986-2010). Soc. Sci. Res. 57, 80-98.

Alvarado, S.E. (2018). The impact of childhood neighborhood disadvantage on adult joblessness and income. Soc. Sci. Res. 70, 1-17.

Alvarado, S.E. (2019). The indelible weight of place: Childhood neighborhood disadvantage, timing of exposure, and obesity across adulthood. Health Place 58, 102159.

Alvarado, S.E. (2020). The Complexities of Race and Place: Childhood Neighborhood Disadvantage and Adult Incarceration for Whites, Blacks, and Latinos. Socius 6, 2378023120927154.

Anderson, L., Sheppard, P., and Monden, C. (2018). Grandparent Effects on Educational Outcomes: A Systematic Review. Sociol. Sci. 5, 114-142.

Andersson, E., and Subramanian, S.V. (2006). Explorations of Neighbourhood and Educational Outcomes for Young Swedes. Urban Stud. 43, 2013-2025.

Andersson, E.K., and Malmberg, B. (2015). Contextual effects on educational attainment in individualised, scalable neighbourhoods: Differences across gender and social class. Urban Stud. 52, 2117-2133.

Andersson, E.K., Lyngstad, T.H., and Sleutjes, B. (2018). Comparing Patterns of Segregation in NorthWestern Europe: A Multiscalar Approach. Eur. J. Popul. 34, 151-168.

Blau, P.M. (1960). Structural Effects. Am. Sociol. Rev. 25, 178-193.

Blau, P., and Duncan, O.D. (1967). The American Occupational Structure (New York: John Wiley \& Sons).

Bobo, L., and Zubrinsky, C.L. (1996). Attitudes on residential integration: Perceived status differences, mere in-group preference, or racial prejudice? Soc. Forces 74, 883-909.

Bowles, S., and Gintis, H. (2002). Schooling in Capitalist America Revisited. Sociol. Educ. 75, 1.

Brännström, L. (2008). Making Their Mark: The Effects of Neighbourhood and Upper Secondary School on Educational Achievement. Eur. Sociol. Rev. 24, 463-478.

Breen, R. (2018). Some Methodological Problems in the Study of Multigenerational Mobility. Eur. Sociol. Rev. 34, 603-611. 
Brooks-Gunn, J., Duncan, G.J., Klebanov, P.K., and Sealand, N. (1993). Do Neighborhoods Influence Child and Adolescent Development? Am. J. Sociol. 99, 353-395.

Cameron, A.C., and Miller, D.L. (2015). A Practitioner's Guide to Cluster-Robust Inference. J. Hum. Resour. $50,317-372$.

Cameron, A.C., Gelbach, J.B., and Miller, D.L. (2011). Robust Inference With Multiway Clustering. J. Bus. Econ. Stat. 29, 238-249.

Chamberlain, G. (1980). Analysis of Covariance with Qualitative Data. Rev. Econ. Stud. 47, 225-238.

Chan, T.W., and Boliver, V. (2013). The Grandparents Effect in Social Mobility: Evidence from British Birth Cohort Studies. Am. Sociol. Rev. 78, 662-678.

Charles, C.Z. (2001). Processes of Residential Segregation. In Urban Inequality: Evidence from Four Cities, A. O’connor, C. Tilly, and L. Bobo, eds. (New York: Russell Sage Foundation), p.

Chetty, R., Hendren, N., Kline, P., and Saez, E. (2014). Where is the land of Opportunity? The Geography of Intergenerational Mobility in the United States *. Q. J. Econ. 129, 1553-1623.

Chetty, R., Hendren, N., and Katz, L.F. (2016). The Effects of Exposure to Better Neighborhoods on Children: New Evidence from the Moving to Opportunity Experiment. Am. Econ. Rev. 106, 855-902.

Chetty, R., Hendren, N., Jones, M.R., and Porter, S.R. (2018). Race and Economic Opportunity in the United States: An Intergenerational Perspective (National Bureau of Economic Research).

Crowder, K., and Downey, L. (2010). Interneighborhood Migration, Race, and Environmental Hazards: Modeling Microlevel Processes of Environmental Inequality. Am. J. Sociol. 115, 1110-1149.

Crowder, K., and South, S.J. (2003). Neighborhood distress and school dropout: the variable significance of community context. Soc. Sci. Res. 32, 659-698.

Crowder, K., and South, S.J. (2005). Race, class, and changing patterns of migration between poor and nonpoor neighborhoods. Am. J. Sociol. 110, 1715-1763.

Crowder, K., and South, S.J. (2011). Spatial and temporal dimensions of neighborhood effects on high school graduation. Soc. Sci. Res. 40, 87-106.

Cutler, D.M., Glaeser, E.L., and Vigdor, J.L. (1999). The rise and decline of the American ghetto. J. Polit. Econ. 107, 455-506.

DeLuca, S., and Jang-Trettien, C. (2020). "Not Just a Lateral Move": Residential Decisions and the Reproduction of Urban Inequality. City Community $n / a$.

DeLuca, S., Wood, H., and Rosenblatt, P. (2019). Why Poor Families Move (And Where They Go): Reactive Mobility and Residential Decisions. City Community.

Diez-Roux, A.V., and Mair, C. (2010). Neighborhoods and health. Biol. Disadv. Socioecon. Status Health $1186,125-145$. 
DiPrete, T.A., and Eirich, G.M. (2006). Cumulative advantage as a mechanism for inequality: A review of theoretical and empirical developments. Annu. Rev. Sociol. 32, 271-297.

Dreier, P., Mollenkopf, J.H., and Swanstrom, T. (2001). Place matters: Metropolitics for the twenty-first century (University Press of Kansas Lawrence).

Elder, G.H., King, V.E., and Conger, R.D. (1996). Attachment to place and migration prospects: A developmental perspective. J. Res. Adolesc. 6, 397-425.

Entwisle, B. (2007). Putting people into place. Demography 44, 687-703.

Fried, M. (1982). Residential attachment: Sources of residential and community satisfaction. J. Soc. Issues 38 , 107-119.

Friedman, S. (2008). Do declines in residential segregation mean stable neighborhood racial integration in metropolitan America? A research note. Soc. Sci. Res. 37, 920-933.

Galster, G., and Sharkey, P. (2017). Spatial Foundations of Inequality: A Conceptual Model and Empirical Overview. RSF 3, 1-33.

Geronimus, A.T., Korenman, S., and Hillemeier, M.M. (1994). Does Young Maternal Age Adversely Affect Child Development? Evidence from Cousin Comparisons in the United States. Popul. Dev. Rev. 20, 585.

Gerson, K., Stueve, A., and Fischer, C. (1977). Attachment to Place. In Networks and Places: Social Relations in the Urban Setting, C. Fischer, R. Jackson, A. Stueve, K. Gerson, L. McCallister Jones, and M. Baldassare, eds. (New York: Free Press), pp. 139-161.

Goux, D., and Maurin, E. (2007). Close neighbours matter: Neighbourhood effects on early performance at school. Econ. J. 117, 1193-1215.

Green, D.P., Strolovitch, D.Z., and Wong, J.S. (1998). Defended Neighborhoods, Integration, and Racially Motivated Crime. Am. J. Sociol. 104, 372-403.

Hällsten, M. (2014). Inequality across three and four generations in Egalitarian Sweden: 1st and 2nd cousin correlations in socio-economic outcomes. Res. Soc. Stratif. Mobil. 35, 19-33.

Harding, D.J. (2003). Counterfactual models of neighborhood effects: The effect of neighborhood poverty on dropping out and teenage pregnancy. Am. J. Sociol. 109, 676-719.

Harding, D.J. (2009). Collateral Consequences of Violence in Disadvantaged Neighborhoods. Soc. Forces 88 , 757-784.

Hertel, F.R., and Groh-Samberg, O. (2014). Class mobility across three generations in the U.S. and Germany. Res. Soc. Stratif. Mobil. 35, 35-52.

von Hippel, P.T. (2007). Regression with Missing Y's: An Improved Strategy for Analyzing Multiply Imputed Data. Sociol. Methodol. 37. 
Iceland, J., and Hernandez, E. (2017). Understanding trends in concentrated poverty: 1980-2014. Soc. Sci. Res. 62, 75-95.

Jæger, M.M. (2012). The Extended Family and Children's Educational Success. Am. Sociol. Rev. 77, 903-922.

Jang-Trettien, C. (2021). House of Cards: Informal Housing Markets and Precarious Pathways to Homeownership in Baltimore. Soc. Probl.

Jargowsky, P.A. (1997). Poverty and place: Ghettos, barrios, and the American city (Russell Sage Foundation).

Jencks, C., and Mayer, S.E. (1990). The Social Consequences of Growing Up in a Poor Neighborhood. L.E. Lynn, and M.G. McGeary, eds. (Washington, D.C.: National Academy Press), p.

Jencks, C., Smith, M., Acland, H., Bane, M.J., Cohen, D., Gintis, H., Heyns, B., and Michelson, S. (1972). Inequality: A Reassessment of the Effect of Family and Schooling in America.

Kauppinen, T.M. (2007). Neighborhood effects in a European city: Secondary education of young people in Helsinki. Soc. Sci. Res. 36, 421-444.

Klebanov, P.K., Brooks-Gunn, J., Chase-Lansdale, L., and Gordon, R.A. (1997). Are Neighborhood Effects on Young Children Mediated by Features of the Home Environment? In Neighborhood Poverty Volume I: Context and Consequences for Children, J. Brooks- Gunn, G.J. Duncan, and J.L. Aber, eds. (New York: Russell Sage Foundation), p.

Korver-Glenn, E. (2021). Race Brokers: Housing Markets and Segregation in 21st Century Urban America (Oxford, New York: Oxford University Press).

Kravitz-Wirtz, N. (2016). Temporal Effects of Child and Adolescent Exposure to Neighborhood Disadvantage on Black/White Disparities in Young Adult Obesity. J. Adolesc. Health 58, 551-557.

Lee, B.A., Oropesa, R.S., and Kanan, J.W. (1994). Neighborhood Context and Residential Mobility. Demography 31, 249.

Lipset, S.M., and Zetterberg, H.L. (1959). Social mobility in industrial societies (University of California Press Berkeley, CA).

Little, R., and Rubin, D. (2020). Statistical Analysis with Missing Data (Hoboken, N.J.: John Wiley \& Sons).

Logan, J.R. (1978). Growth, politics, and the stratification of places. Am. J. Sociol. 84, 404-416.

Logan, J.R., and Collver, O.A. (1983). Residents' Perceptions of Suburban Community Differences. Am. Sociol. Rev. 48, 428.

Logan, J.R., Stults, B.J., and Farley, R. (2004). Segregation of minorities in the metropolis: two decades of change. Demography 41,1-22.

Manduca, R., and Sampson, R.J. (2019). Punishing and toxic neighborhood environments independently predict the intergenerational social mobility of black and white children. Proc. Natl. Acad. Sci. 116, 77727777. 
Mare, R.D. (2011). A Multigenerational View of Inequality. Demography 48, 1-23.

Massey, D.S. (2007). Categorically Unequal: The American Stratification System (Russell Sage Foundation).

Massey, D.S., and Denton, N. (1993). American Apartheid: Segregation and the Making of the Underclass (Cambridge: Harvard University Press).

Massey, D.S., Wagner, B., Donnelly, L., McLanahan, S., Brooks-Gunn, J., Garfinkel, I., Mitchell, C., and Notterman, D.A. (2018). Neighborhood Disadvantage and Telomere Length: Results from the Fragile Families Study. RSF Russell Sage Found. J. Soc. Sci. 4, 28-42.

Matthews, S.A., and Yang, T.-C. (2013). Spatial Polygamy and Contextual Exposures (SPACEs): Promoting Activity Space Approaches in Research on Place And Health. Am. Behav. Sci. 57, 1057-1081.

McAvay, H., and Safi, M. (2018). Is there really such thing as immigrant spatial assimilation in France? Desegregation trends and inequality along ethnoracial lines. Soc. Sci. Res. 73, 45-62.

Miller, D., Shenhave, N., and Grosz, M. (2018). Selection into Identification in Fixed Effects Models, with Application to Head Start.

Mulligan, C.B. (1997). Parental priorities and economic inequality (University of Chicago Press).

Pepper, J.V. (2002). Robust inferences from random clustered samples: an application using data from the panel study of income dynamics. Econ. Lett. 75, 341-345.

Pfeffer, F.T. (2014). Multigenerational Approaches to Social Mobility. A Multifaceted Research Agenda. Res. Soc. Stratif. Mobil. 35, 1-12.

Pfeffer, F.T., and Killewald, A. (2018). Generations of Advantage. Multigenerational Correlations in Family Wealth. Soc. Forces 96, 1411-1442.

Pfeffer, F.T., and Killewald, A. (2019). Intergenerational Wealth Mobility and Racial Inequality. Socius 5 , 2378023119831799.

Plotnick, R.D., and Hoffman, S.D. (1999). The effect of neighborhood characteristics on young adult outcomes: Alternative estimates. Soc. Sci. Q. 80,1-18.

Quillian, L. (2003). How long are exposures to poor neighborhoods? The long-term dynamics of entry and exit from poor neighborhoods. Popul. Res. Policy Rev. 22, 221-249.

Quillian, L., and Lagrange, H. (2016). Socioeconomic Segregation in Large Cities in France and the United States. Demography 53, 1051-1084.

Reardon, S.F., Fox, L., and Townsend, J. (2015). Neighborhood Income Composition by Household Race and Income, 1990-2009. Ann. Am. Acad. Pol. Soc. Sci. 660, 78-97.

van de Rijt, A., Siegel, D., and Macy, M. (2009). Neighborhood Chance and Neighborhood Change: A Comment on Bruch and Mare. Am. J. Sociol. 114, 1166-1180. 
Roksa, J., and Potter, D. (2011). Parenting and Academic Achievement: Intergenerational Transmission of Educational Advantage. Sociol. Educ. 84, 299-321.

Royston, P. (2005). Multiple imputation of missing values: Update of ice. Stata J. 5, 527-536.

Royston, P., and White, I.R. (2011). Multiple Imputation by Chained Equations (MICE): Implementation in Stata. J. Stat. Softw. 45, 1-20.

Sampson, R. (2012). Great American city : Chicago and the enduring neighborhood effect (Chicago, IL: University of Chicago Press).

Sampson, R.J., Morenoff, J.D., and Gannon-Rowley, T. (2002). Assessing "Neighborhood Effects": Social Processes and New Directions in Research. Annu. Rev. Sociol. 28, 443-478.

Sampson, R.J., Sharkey, P., and Raudenbush, S.W. (2008). Durable effects of concentrated disadvantage on verbal ability among African-American children. Proc. Natl. Acad. Sci. U. S. A. 105, 845-852.

Schelling, T.C. (1971). Dynamic Models of Segregation. J. Math. Sociol. 1, 143-186.

Sewell, W.H., and Hauser, R.M. (1975). Education, Occupation, and Earnings: Achievement in the Early Career (New York: Academic Press).

Sharkey, P. (2008). The Intergenerational Transmission of Context. Am. J. Sociol. 113, 931-969.

Sharkey, P. (2013). Stuck in Place: Urban Neighborhoods and the End of Progress Toward Racial Equality (Chicago, IL: University of Chicago Press).

Sharkey, P. (2014). Spatial Segmentation and the Black Middle Class. Am. J. Sociol. 119, 903-954.

Sharkey, P., and Elwert, F. (2011). The Legacy of Disadvantage: Multigenerational Neighborhood Effects on Cognitive Ability. Am. J. Sociol. 116, 1934-1981.

Sharkey, P., and Faber, J. (2014). Where, When, Why, and for Whom Do Residential Contexts Matter? Moving Away from the Dichotomous Understanding of Neighborhood Effects. Annu. Rev. Sociol. 40, 127.21.

Sharkey, P., Schwartz, A.E., Ellen, I.G., and Lacoe, J. (2014). High stakes in the classroom, high stakes on the street: The effects of community violence on students' standardized test performance. Sociol. Sci. 1, 199-220.

Shih, M., Dumke, K.A., Goran, M.I., and Simon, P.A. (2012). The association between community-level economic hardship and childhood obesity prevalence in Los Angeles. Pediatr. Obes. 8, 411-417.

Small, M.L., and Newman, K. (2001). Urban poverty after The Truly Disadvantaged: The rediscovery of the family, the neighborhood, and culture. Annu. Rev. Sociol. 27, 23-45.

Solon, G. (1992). Intergenerational Income Mobility in the United States. Am. Econ. Rev. 82, 393-408.

Solon, G. (2014). Theoretical models of inequality transmission across multiple generations. Res. Soc. Stratif. Mobil. 35, 13-18. 
Song, X. (2016). Diverging Mobility Trajectories: Grandparent Effects on Educational Attainment in Oneand Two-Parent Families in the United States. Demography 53, 1905-1932.

Song, X., and Mare, R.D. (2015). Prospective Versus Retrospective Approaches to the Study of Intergenerational Social Mobility. Sociol. Methods Res. 44, 555-584.

Song, X., and Mare, R.D. (2019). Shared Lifetimes, Multigenerational Exposure, and Educational Mobility. Demography 56, 891-916.

Song, X., Campbell, C.D., and Lee, J.Z. (2015). Ancestry Matters: Patrilineage Growth and Extinction. Am. Sociol. Rev. 80, 574-602.

South, S.J., and Crowder, K.D. (1997). Escaping distressed neighborhoods: Individual, community, and metropolitan influences. Am. J. Sociol. 102, 1040-1084.

Tammaru, T., Marcin'czak, S., Aunap, R., van Ham, M., and Janssen, H. (2020). Relationship between income inequality and residential segregation of socioeconomic groups. Reg. Stud. 54, 450-461.

Timberlake, J.M. (2007). Racial and ethnic inequality in the duration of children's exposure to neighborhood poverty and affluence. Soc. Probl. 54, 319-342.

Timberlake, J.M. (2009a). Effects of household and neighborhood characteristics on children's exposure to neighborhood poverty and affluence. Soc. Sci. Res. 38, 458-476.

Timberlake, J.M. (2009b). “Scratchin' and Surviving” or “Movin' on Up?” Two Sources of Change in Children's Neighborhood SES. Popul. Res. Policy Rev. 28, 195-219.

Turley, R.N.L. (2003). Are Children of Young Mothers Disadvantaged Because of Their Mother's Age or Family Background? Child Dev. 74, 465-474.

Turner, M.A., Ross, S., Galster, G.C., and Yinger, J. (2002). Discrimination in Metropolitan Housing Markets: National Results from Phase 1 of the Housing Discrimination Study (HDS) (University of Connecticut, Department of Economics).

Vartanian, T.P., and Buck, P.W. (2005). Childhood and Adolescent Neighborhood Effects on Adult Income: Using Siblings to Examine Differences in Ordinary Least Squares and Fixed-Effect Models. Soc. Serv. Rev. 79, 60-94.

Vartanian, T.P., and Houser, L. (2010). The Effects of Childhood Neighborhood Conditions on Self-reports of Adult Health. J. Health Soc. Behav. 51, 291-306.

Wilson, W.J. (1987). The Truly Disadvantaged: The Inner City, the Underclass, and Public Policy (Chicago: University of Chicago Press).

Wilson, W.J. (1991). Studying Inner-City Social Dislocations: The Challenge of Public Agenda Research. Am. Sociol. Rev. 56, 1-14.

Wilson, W.J. (1996). When Work Disappears: The World of the New Urban Poor (New York: Alfred A. Knopf). 
Wodtke, G.T. (2013). Duration and Timing of Exposure to Neighborhood Poverty and the Risk of Adolescent Parenthood. Demography 50, 1765-1788.

Wodtke, G.T., and Parbst, M. (2017). Neighborhoods, Schools, and Academic Achievement: A Formal Mediation Analysis of Contextual Effects on Reading and Mathematics Abilities. Demography 54, 1653 1676.

Wodtke, G.T., Harding, D.J., and Elwert, F. (2011). Neighborhood Effects in Temporal Perspective The Impact of Long-Term Exposure to Concentrated Disadvantage on High School Graduation. Am. Sociol. Rev. 76, 713-736.

Wodtke, G.T., Elwert, F., and Harding, D.J. (2016). Neighborhood Effect Heterogeneity by Family Income and Developmental Period. Am. J. Sociol. 121, 1168-1222.

Yinger, J. (1995). Closed doors, opportunities lost: The continuing costs of housing discrimination (Russell Sage Foundation).

York Cornwell, E., and Cagney, K.A. (2017). Aging in Activity Space: Results From Smartphone-Based GPSTracking of Urban Seniors. J. Gerontol. Ser. B 72, 864-875.

Zeng, Z., and Xie, Y. (2014). The Effects of Grandparents on Children's Schooling: Evidence From Rural China. Demography 51, 599-617.

(1992). Place Attachment: Human Behavior and Environment. Advances in Theory and Research Vol. 12 (New York: Plenum). 


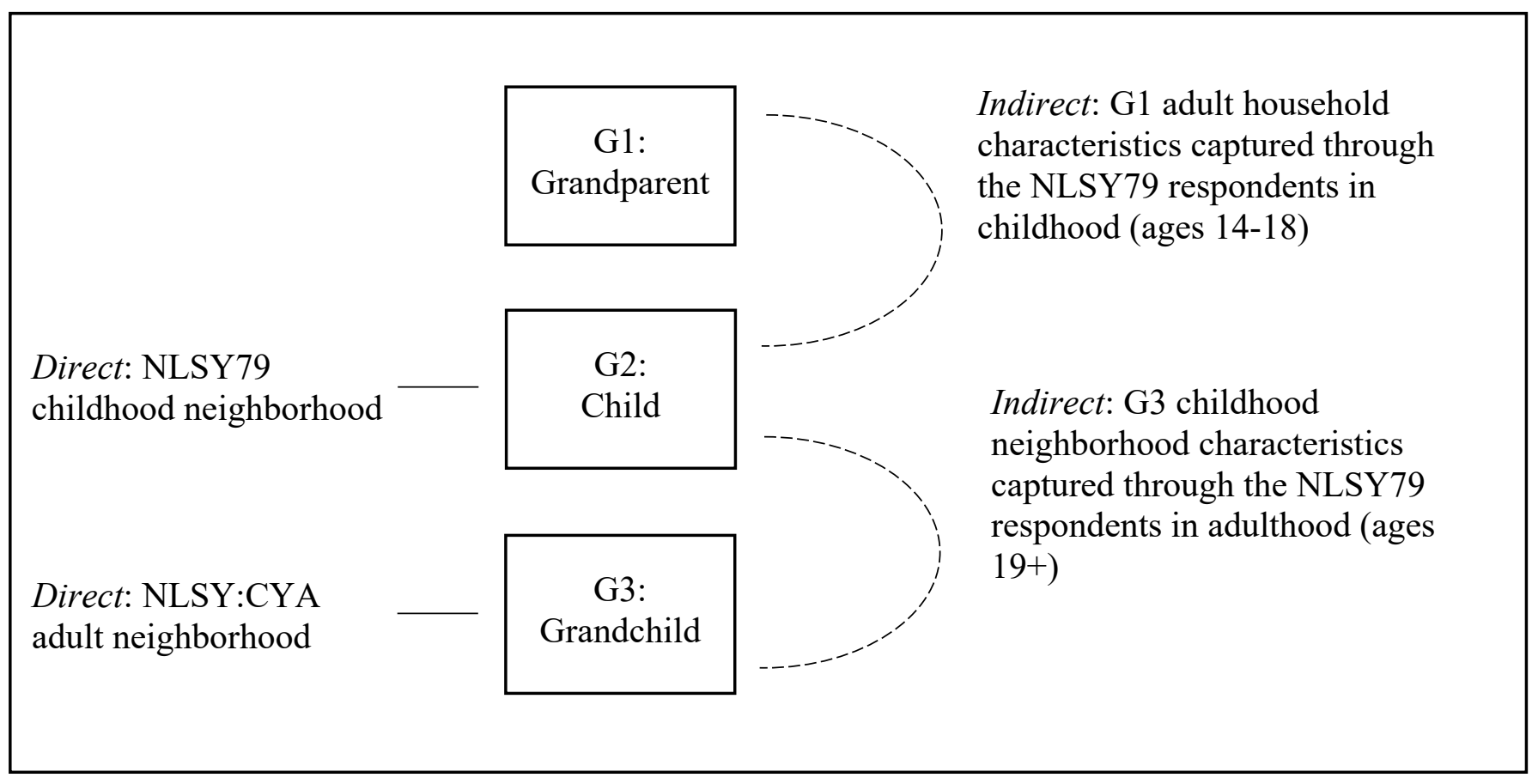

Figure 1. Generational structure of the linked NLSY79 and NLSY:CYA datasets. 


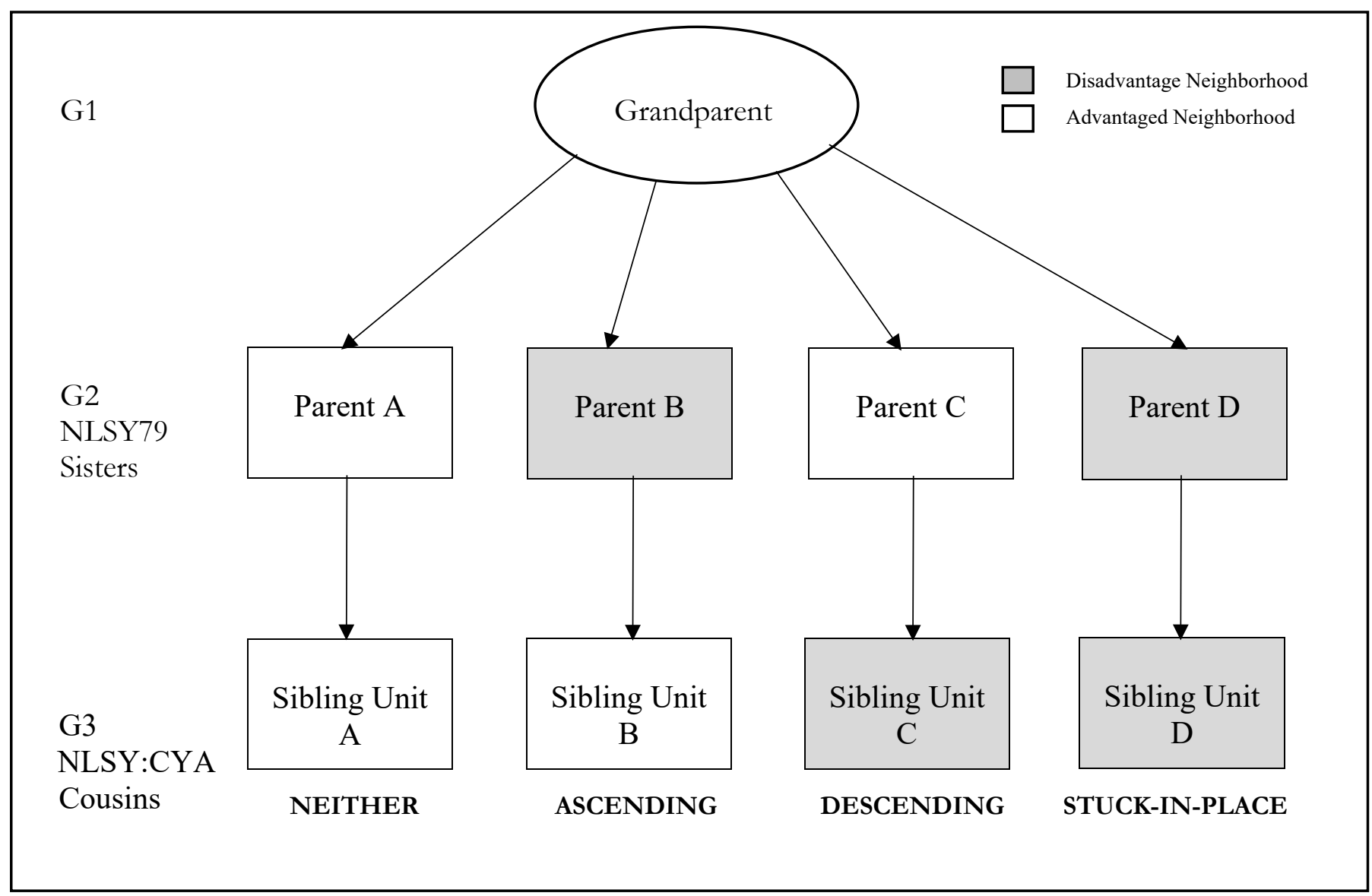

Figure 2. Intergenerational family trajectories. These four family trajectories among G2 sisters and G3 cousins represent the four categories of the independent variable: neither, ascending, descending, and stuck-in-place family profiles. The reference category in all models is neither. G3 sibling units contain one or more siblings. 


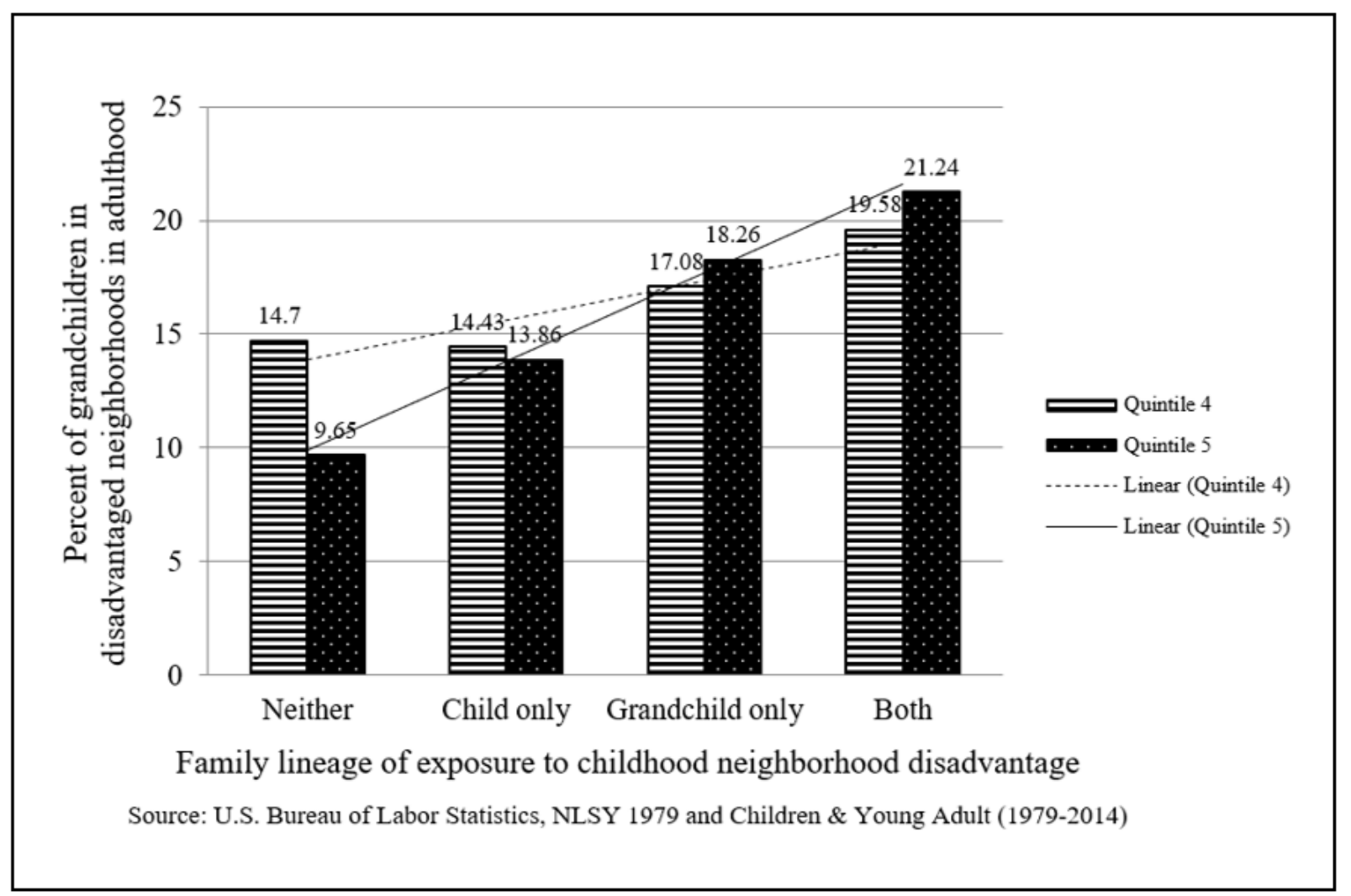

Figure 3. The percent of G3 "grandchildren" living in disadvantaged neighborhoods in adulthood as a function of the family lineage of exposure to childhood neighborhood disadvantage. 


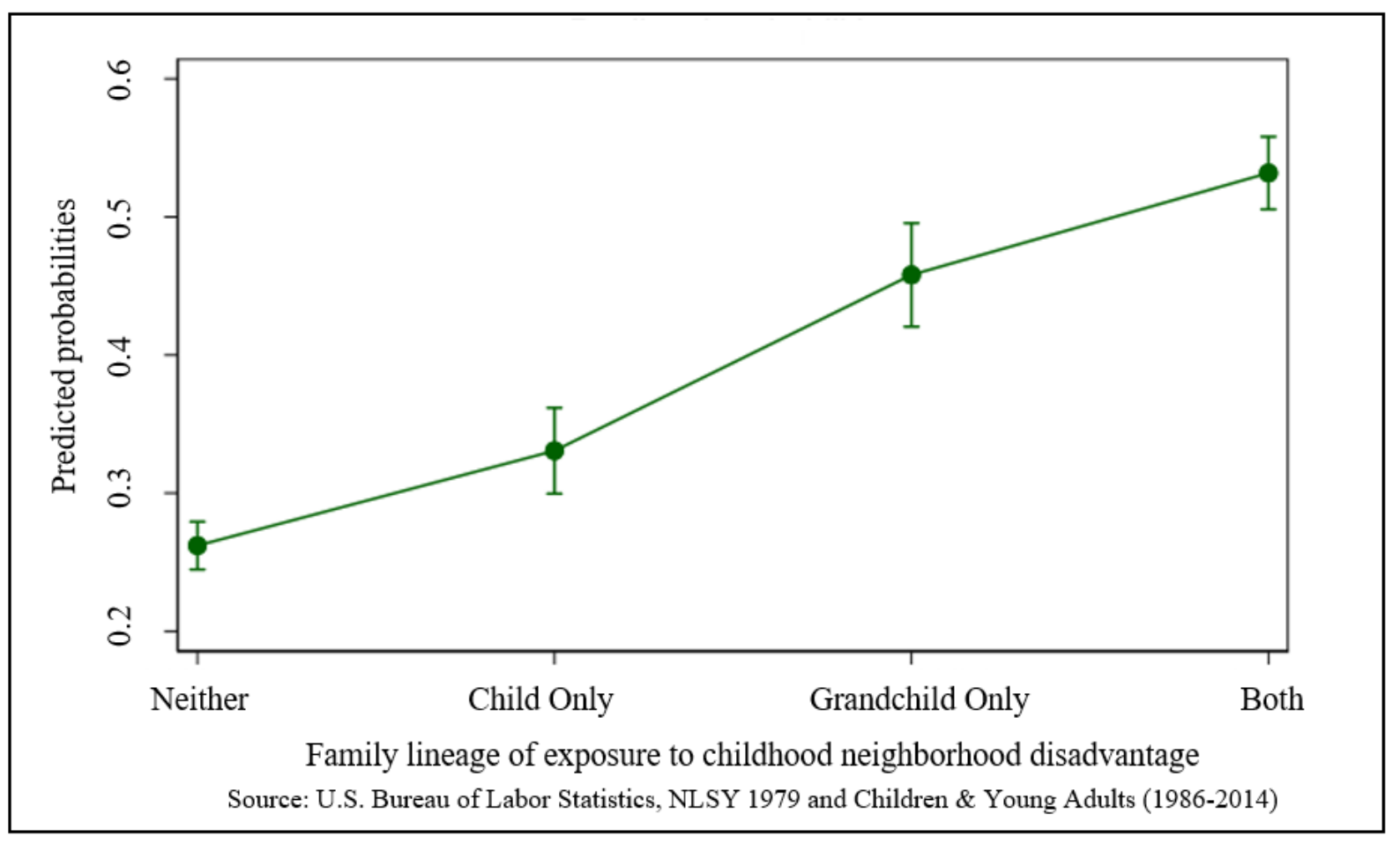

Figure 4. Predicted probabilities of G3 "grandchildren's" adult exposure to neighborhood disadvantage as a function of the family lineage of exposure to childhood neighborhood disadvantage: Unadjusted logistic regression model (Appendix A). 


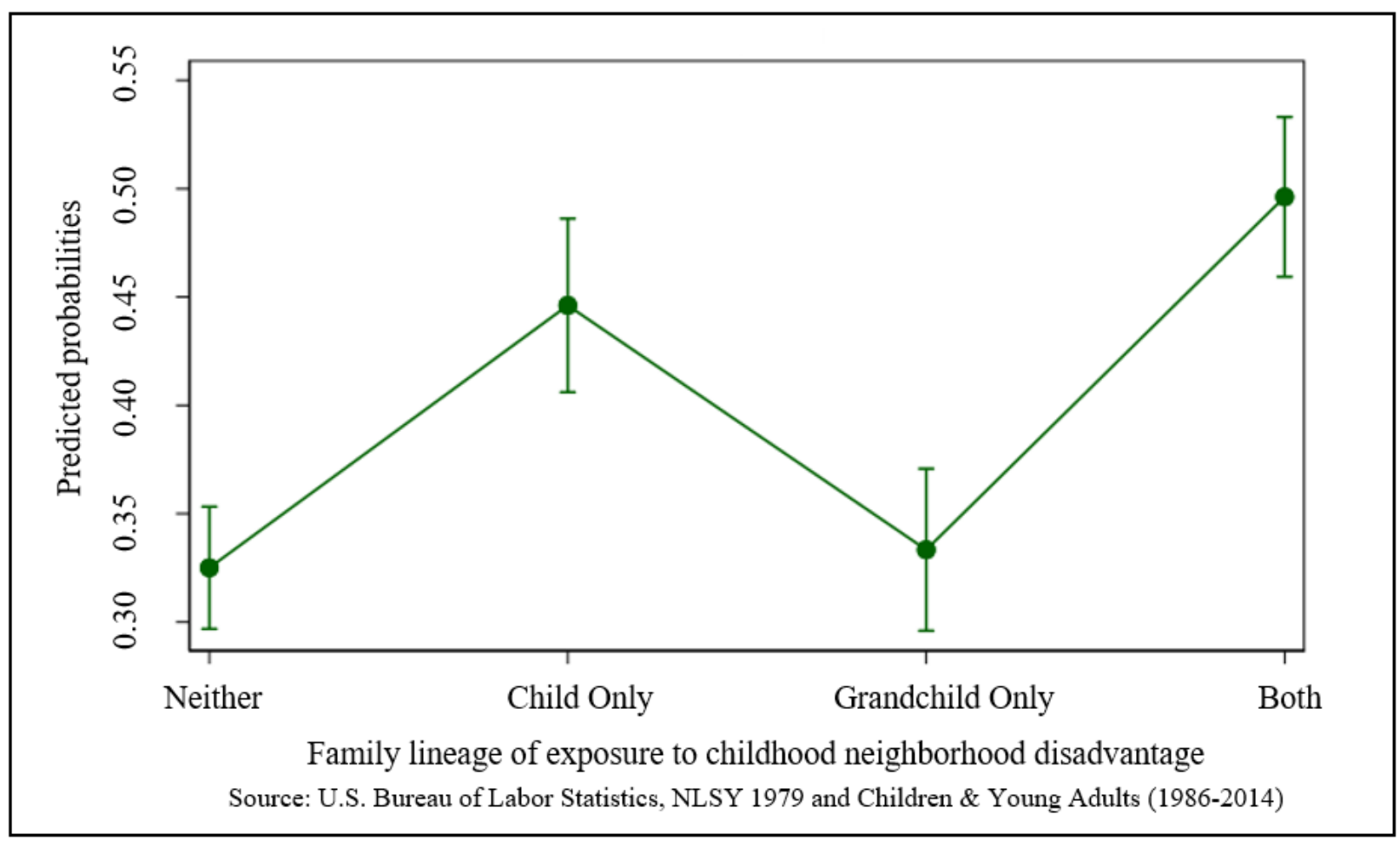

Figure 5. Predicted probabilities of G3 "grandchildren's" adult exposure to neighborhood disadvantage as a function of the family lineage of exposure to childhood neighborhood disadvantage: Fully adjusted linear probability model with cousin fixed effects (Table 3). 
Table 1. Descriptive statistics for the analytical sample of NLSY respondents

\section{Grandparent (G1) adult household characteristics}

Number of children in household

Grandmother years of education

Single parent

Grandmother USA born

Grandfather USA born

Grandmother working

Grandfather working

Grandparents' mean household logged income

Grandparents ever in poverty

\begin{tabular}{cc} 
Mean & $\begin{array}{c}\text { Standard deviation } \\
\text { (between) }\end{array}$ \\
\hline 4.25 & 2.67 \\
10.26 & 3.91 \\
0.66 & 0.46 \\
0.89 & 0.31 \\
0.90 & 0.30 \\
0.68 & 0.46 \\
0.91 & 0.27 \\
9.54 & 0.95 \\
0.51 & 0.49 \\
& \\
0.48 & 0.48 \\
0.23 & 0.42 \\
0.23 & 0.38 \\
0.34 & 0.46 \\
& \\
& \\
& \\
& \\
&
\end{tabular}

Multigenerational (G2 and G3) neighborhood disadvantage

Neither:

Neither G2 nor G3 were exposed to neighborhood disadvantage in childhood

Ascending families:

Only G2 was exposed to neighborhood disadvantage in childhood

Descending families:

Only G3 was exposed to neighborhood disadvantage in childhood

Stuck-in-place families:

Both G2 and G3 were exposed to neighborhood disadvantage in childhood

\section{Grandchild (G3) outcome}

G3 exposed to neighborhood disadvantage in adulthood

0.40

Source: NLSY79 1979-2014; NLSY:CYA 1986-2014 
Table 2. Adjusted logistic regression results for the association between multigenerational (G2 and G3) exposure to childhood neighborhood disadvantage and grandchildren's (G3) mean adult neighborhood disadvantage exposure: Quintiles 1-3 vs. 4-5.

\section{Multigenerational (G2 and G3) neighborhood disadvantage}

Ascending families:

Only G2 was exposed to neighborhood disadvantage in childhood Descending families:

Only G3 was exposed to neighborhood disadvantage in childhood + Observed adjustments Stuck-in-place families:

Both G2 and G3 were exposed to neighborhood disadvantage in childhood Constant

Observations

4,760

Notes: The reference category is neither G2 nor G3 were exposed to neighborhood disadvantage in childhood.

Observed adjustments for G2's childhood include the following characteristics of G1 in adulthood: Number of children in the household, grandmother's years of education, single parent, grandmother foreign born, grandfather foreign born, grandmother working, grandfather working, grandparents' mean household logged income, grandparents ever in poverty.

Coefficients are shown.

Robust standard errors (in parentheses) are corrected for clustering. $\dagger \mathrm{p}<.10 ; * \mathrm{p}<.05 ; * * \mathrm{p}<.01 ; * * * \mathrm{p}<.001$

Source: NLSY79 1979-2014; NLSY:CYA 1986-2014 
Table 3. Linear probabilty model results for the association between multigenerational (G2 and G3) exposure to childhood neighborhood disadvantage and grandchildren's (G3) mean adult neighborhood disadvantage exposure: Quintiles 1-3 vs. 4-5.

\section{Multigenerational (G2 and G3) neighborhood disadvantage}

Ascending families:

Only G2 was exposed to neighborhood disadvantage in childhood

Descending families:

Only G3 was exposed to neighborhood disadvantage in childhood

Stuck-in-place families:

Both G2 and G3 were exposed to neighborhood disadvantage in childhood

Constant

Observations

2,400

Notes: The reference category is neither G2 nor G3 were exposed to neighborhood disadvantage in childhood.

Observed adjustments for G2's childhood include the following characteristics of G1 in adulthood: Number of children in the household, grandmother's years of education, single parent, grandmother foreign born, grandfather foreign born, grandmother working, grandfather working, grandparents' mean household logged income, grandparents ever in poverty.

Coefficients are shown.

Robust standard errors (in parentheses) are corrected for clustering. $\dagger p<.10 ; * \mathrm{p}<.05 ; * * \mathrm{p}<.01 ; * * * \mathrm{p}<.001$

Source: NLSY79 1979-2014; NLSY:CYA 1986-2014 
Table 4. Logistic regression results for the association between multigenerational (G2 and G3) exposure to childhood neighborhood disadvantage and grandchildren's (G3) mean adult neighborhood disadvantage exposure: Quintiles 1-4 vs. 5.

Multigenerational (G2 and G3) neighborhood disadvantage

Zero + Observed

order adjustments

Ascending families:

Only G2 was exposed to neighborhood disadvantage in childhood Descending families:

Only G3 was exposed to neighborhood disadvantage in childhood Stuck-in-place families:

Both G2 and G3 were exposed to neighborhood disadvantage in childhood

Constant

$0.78 * * * \quad 0.35$

$(0.22)$

$(0.28)$

$1.20 * * * \quad 1.08 * * *$

$(0.08) \quad(0.09)$

$1.76 * * * \quad 1.99 * * *$

$(0.16) \quad(0.21)$

$-1.66 * * * \quad-2.21 * * *$

$(0.04)$

Observations

5,420

Notes: The reference category is neither G2 nor G3 were exposed to neighborhood disadvantage in childhood.

Observed adjustments for G2's childhood include the following characteristics of G1 in adulthood: Number of children in the household, grandmother's years of education, single parent, grandmother foreign born, grandfather foreign born, grandmother working, grandfather working, grandparents' mean household logged income, grandparents ever in poverty.

Coefficients are shown.

Robust standard errors (in parentheses) are corrected for clustering.

$\dagger \mathrm{p}<.10 ; * \mathrm{p}<.05 ; * * \mathrm{p}<.01 ; * * * \mathrm{p}<.001$

Source: NLSY79 1979-2014; NLSY:CYA 1986-2014 
Table 5. Linear probabilty model results for the association between multigenerational (G2 and G3) exposure to childhood neighborhood disadvantage and grandchildren's (G3) mean adult neighborhood disadvantage exposure: Quintiles 1-4 vs. 5.

Multigenerational (G2 and G3) neighborhood disadvantage

Ascending families:

Only G2 was exposed to neighborhood disadvantage in childhood Descending families:

+ Cousin fixed effects

Only G3 was exposed to neighborhood disadvantage in childhood Stuck-in-place families:

Both G2 and G3 were exposed to neighborhood disadvantage in childhood

Constant

Observations 2,400

Notes: The reference category is neither G2 nor G3 were exposed to neighborhood disadvantage in childhood.

Observed adjustments for G2's childhood include the following characteristics of G1 in adulthood: Number of children in the household, grandmother's years of education, single parent, grandmother foreign born, grandfather foreign born, grandmother working, grandfather working, grandparents' mean household logged income, grandparents ever in poverty.

Coefficients are shown.

Robust standard errors (in parentheses) are corrected for clustering. $\dagger \mathrm{p}<.10 ; * \mathrm{p}<.05 ; * * \mathrm{p}<.01 ; * * * \mathrm{p}<.001$

Source: NLSY79 1979-2014; NLSY:CYA 1986-2014 
Table 6. Regression results for the association between multigenerational (G2 and G3) exposure to childhood neighborhood disadvantage and grandchildren's (G3) ever exposure to adult neighborhood disadvantage.

\begin{tabular}{|c|c|c|c|c|c|c|}
\hline & \multicolumn{3}{|c|}{ Neighborhood quintiles $1-3$ vs. $4-5$} & \multicolumn{3}{|c|}{ Neighborhood quintiles $1-4$ vs. 5} \\
\hline & (1) & (2) & (3) & (4) & (5) & (6) \\
\hline & Logistic & Logistic & Linear Probability Model & Logistic & Logistic & Linear Probability Model \\
\hline & & + Observed & + Observed adjustments & & + Observed & + Observed adjustments \\
\hline & Zero order & adjustments & and cousin fixed effects & Zero order & adjustments & and cousin fixed effects \\
\hline \multicolumn{7}{|l|}{ Multigenerational (G2 and G3) neighborhood disadvantage } \\
\hline Ascending families: & $0.21^{* *}$ & 0.10 & $0.04 \dagger$ & $0.73^{* * *}$ & 0.24 & $0.24 * * *$ \\
\hline Only G2 was exposed to neighborhood disadvantage in childhood & $(0.08)$ & $(0.09)$ & $(0.02)$ & $(0.21)$ & $(0.24)$ & $(0.03)$ \\
\hline Descending families: & $1.18^{* * *}$ & $1.03^{* * *}$ & 0.01 & $1.11^{* * *}$ & $0.89^{* * *}$ & $0.05^{*}$ \\
\hline Only G3 was exposed to neighborhood disadvantage in childhood & $(0.11)$ & $(0.12)$ & $(0.01)$ & $(0.08)$ & $(0.09)$ & $(0.03)$ \\
\hline Stuck-in-place families: & $1.32 * * *$ & $1.05^{* * *}$ & $0.07^{* *}$ & $1.63^{* * *}$ & $1.73 * * *$ & $0.30 * * *$ \\
\hline Both G2 and G3 were exposed to neighborhood disadvantage in childhood & $(0.09)$ & $(0.10)$ & $(0.02)$ & $(0.19)$ & $(0.26)$ & $(0.03)$ \\
\hline \multirow[t]{2}{*}{ Constant } & $0.39 * * *$ & $1.01^{*}$ & $1.10^{* * *}$ & $-0.43 * * *$ & 0.22 & $1.46^{* * *}$ \\
\hline & $(0.04)$ & $(0.45)$ & $(0.14)$ & $(0.03)$ & $(0.39)$ & $(0.16)$ \\
\hline Observations & 5,420 & 4,760 & 2,400 & 5,420 & 4,760 & 2,400 \\
\hline
\end{tabular}

Notes: The reference category is neither G2 nor G3 were exposed to neighborhood disadvantage in childhood.

Observed adjustments for G2's childhood include the following characteristics of G1 in adulthood: Number of children in the household, grandmother's years of education, single parent, grandmother foreign born, grandfather foreign born, grandmother working, grandfather working, grandparents' mean household logged income, grandparents ever in poverty.

Coefficients are shown.

Robust standard errors (in parentheses) are corrected for clustering.

$\dagger \mathrm{p}<.10 ;{ }^{*} \mathrm{p}<.05 ; * * \mathrm{p}<.01 ; * * * \mathrm{p}<.001$

Source: NLSY79 1979-2014; NLSY:CYA 1986-2014 
Appendix A. Zero-order logistic regression results for the association between multigenerational (G2 and G3) exposure to childhood neighborhood disadvantage and grandchildren's (G3) mean adult neighborhood disadvantage exposure:

Quintiles 1-3 vs. 4-5.

Multigenerational (G2 and G3) neighborhood disadvantage

Zero order

Ascending families:

$0.33 * * *$

Only G2 was exposed to neighborhood disadvantage in childhood

Descending families:

Only G3 was exposed to neighborhood disadvantage in childhood

Stuck-in-place families:

Both G2 and G3 were exposed to neighborhood disadvantage in childhood

Constant

Observations

5,420

Notes: The reference category is neither G2 nor G3 were exposed to neighborhood disadvantage in childhood.

Observed adjustments for G2's childhood include the following characteristics of G1 in adulthood: Number of children in the household, grandmother's years of education, single parent, grandmother foreign born, grandfather foreign born, grandmother working, grandfather working, grandparents' mean household logged income, grandparents ever in poverty.

Coefficients are shown.

Robust standard errors (in parentheses) are corrected for clustering.

$\dagger \mathrm{p}<.10 ; * \mathrm{p}<.05 ; * * \mathrm{p}<.01 ; * * * \mathrm{p}<.001$

Source: NLSY79 1979-2014; NLSY:CYA 1986-2014 
Appendix B. Data and Methods Notes

Defining Neighborhood Contexts

- U.S. Census Tracts: We follow previous neighborhood effects researchers by defining neighborhoods as Census tracts (Brooks-Gunn et al., 1993; Vartanian and Buck, 2005; Wodtke et al., 2016). The Geolytics Neighborhood Change database provides data on tract socioeconomic characteristics for 1980, 1990, and 2000 using the Census long form, normalized to 2000 tract boundaries, and data from the 2005-2009 American Communities Survey (ACS) that is also normalized to 2000 tract boundaries. The 2010 ACS is no longer normalized to 2000 tract boundaries, so it is incompatible with the NLSY79 geocode data (which is only normalized to 2000 and before). We also follow the previous literature and linearly interpolate neighborhood conditions for the years in between census enumeration (Aaronson, 1998).

- Extra-Local Geographies: Census tracts are typically used in neighborhood research and are a geographic unit perceived to provide an accurate depiction of the structural conditions that can impact individuals' outcomes across the life course (Jencks and Mayer, 1990; Massey and Denton, 1993; Wilson, 1987). Other geographies like commuting zones (Chetty et al., 2014) and block faces (Sharkey et al., 2014) have been utilized in empirical investigations as well. However, new research has attempted to break away from these governmentally defined geographic units, instead relying on the subjects' own interpretation of their neighborhoods or boundaries contingent upon their physical movement throughout the day (Matthews and Yang, 2013; York Cornwell and Cagney, 2017). A subjective measure, such as the one we employ for G3 in adulthood, relies on personal interpretation and thus has the possibility to alter our understanding of how we conceptualize and measure neighborhood context, providing a qualitative distinction and contributing to the body of knowledge on extra-local geographies.

- Subjective Measures of Neighborhood Conditions: Subjective neighborhood measures may more accurately capture the places where respondents spend their time compared to bureaucratic definitions of neighborhoods provided by the government. Still, there may be some drawbacks. For instance, respondents may have different standards or reference frames depending on their upbringing. This may suppress the association between childhood and adult neighborhood disadvantage. Further, objective neighborhood conditions are tied to one's day-to-day physical movements and thus might influence how residents define their neighborhoods subjectively.

- NLSY:CYA Neighborboods in Early Adulthood: G3 from the NLSY:CYA who go to college may artificially inflate intergenerational similarity in neighborhood attainment. However, such inflation may not have an overwhelming impact on our conclusions. One reason is that the potential age range for when G3 are in college only covers a fraction of the total years that we measure G3 adult neighborhood conditions. Traditionally, students enter college at 18 and the median months it takes to complete college is 52

(https://nces.ed.gov/fastfacts/display.asp?id=569). This puts the average age of college completion at 22. These 4 years cover at most 3 of the G3 adult waves because the U.S. Bureau of Labor Statistics (BLS) only surveys NLSY:CYA respondents every other year (e.g., a college enrolled G3 respondent could potentially be surveyed at ages 18, 20, and 22). 
Meanwhile, we continue to use measurements for G3 neighborhoods well into adulthood. Further, using age 19 as our floor does not affect NLSY:CYA respondents who did not go to college and are likely independent of their parents.

National Longitudinal Survey of Youth Samples (NLSY79 and NLSY:CYA)

- Sample Size: In accordance with BLS rules regarding restricted tract-level data, we round all sample sizes.

- Supplemental Sample: The BLS dropped two groups of G2 NLSY79 respondents: (1) approximately 1,100 male and female members of the 1,300-person military subsample (dropped after the 1984 survey) and (2) approximately 1,650 male and female members of the supplemental poor white subsample (dropped after the 1990 survey).

- Imputation: All G2 NLSY79 respondents had at least one wave of data on their childhood household characteristics and tract locations between 1979 and 1983. If data on G2's childhood household characteristics or tract characteristics were missing in a particular childhood wave between 1979 and 1983, but the family met all other criteria for inclusion into the sample, we imputed to correct for missingness using chained equations imputation procedures in Stata (Allison, 2002; von Hippel, 2007; Royston, 2005). The imputation technique addresses missingness from item non-response and assumes missing at random (for a fuller discussion of the assumptions involved in imputing for missing data, see Little and Rubin, 2020; Royston and White, 2011).

- NLSY79 and NLSY:CYA Kinship Structure: In 1986, when the first round of surveys for the NLSY:CYA took place, 2,922 G2 mothers reported having 5,255 G3 youth whose ages ranged from 0 to 23. In 2014, there were 3,088 mothers interviewed, 276 respondents under age 15 denoted as "children" by the BLS interviewed, and 5,735 respondents ages 15 and older denoted as "young adults" who were interviewed. As such, the size of the G3 NLSY:CYA sample has increased over time and depends on the number of youth born to female G2 NLSY79 respondents. The number of interviewed youth in a given wave also depends on any wave-specific non-interviews. On average, 6,787 NLSY:CYA children of NLSY79 mothers have been interviewed at each wave between 1986 and 2014. Beginning in 2010 , young adults over age 30 are only interviewed every four years.

- Variation in Intergenerational Exposure: G2 sisters were separated by 2.15 years on average. This is close to the 3-year difference between respondents that Aaronson (1998) reported. Further, he found that larger ( $4-5$ year) age differences did not substantially change the results (but did decrease precision), giving us confidence that the neighborhood changes we are picking up are not simply measurement noise (Aaronson 1998). Ultimately, the variation that we are using is not solely between G2 sisters. Instead, our models capture variation in intergenerational exposure that considers G3 as well. For example, when we estimate differences between ascending vs. neither family trajectories, one G2 sister grew up in a disadvantaged neighborhood and the other did not - variation in intergenerational exposure is stemming from the intervening years of measurement after an older sister turned 19. However, when we estimate differences between descending vs. neither family trajectories, the two G2 sisters grew up in advantaged neighborhoods and the variation in intergenerational exposure here comes from G3 cousins and not from G2 sisters. When we estimate differences between stuck-in-place vs. neither family trajectories, the two G2 sisters 
grew up in different neighborhood typologies and so did the cousins in G3. Thus, our models rely on variation from both the G2 and G3 generations.

- Generalizability: Like the PSID Child Development Supplement (CDS) before it, the NLSY:CYA is not nationally representative. Rather, the PSID CDS and the NLSY:CYA both represent the children of nationally representative samples of the U.S. population in 1968 and in 1979, respectively. On average, NLSY79 women have had about two children spaced 3.5 years apart. By cross-referencing survey responses using the longitudinal framework of the data, administrators for the NLSY have improved precision and minimized measurement error. Still, some data are not available in some waves because some children were either not living with the mother, the child was deceased, or the child simply did not answer the survey in a given wave.

- Data Truncation: Given that the minimum age of the NLSY79 cohort respondents is 14 when first surveyed in 1979, we do not have a complete history of G2's childhood neighborhood conditions. The maximum age of the NLSY:CYA sample is 44 as of the 2014 wave meaning we can assess the neighborhood conditions of G3 across a wide swath of adulthood.

Fixed Effects Methodology

- Cousin Fixed Effects: We invoke cousin fixed effects to at least partially account for some of the unobserved theoretical mechanisms that Sharkey (2008) describes as potential conduits for influence underlying intergenerational neighborhood mobility. Conceptually, controlling for unobserved confounders at the grandparent-level may address any concern that fixed characteristics among cousins like genes or housing constraints stemming from structural discrimination or individual housing preferences that were present in previous generations would bias our estimates. Although prior neighborhood studies have used sibling fixed effects (Aaronson, 1998; Alvarado, 2016a; Plotnick and Hoffman, 1999; Vartanian and Buck, 2005), we are among the first in the literature to use cousins to control for unobserved confounders experienced by the grandparent generation.

- Sample for Cousin Fixed Effects: Our cousin fixed effects analysis excludes over 9,000 G3 children due to our stated inclusion criteria. Most G3 children are lost because their mothers were over age 18 in 1979, because they did not have a cousin, or because their mothers were in the dropped supplemental G2 military and poor white subsamples.

- Mean Deviation Algorithm for Cousin Fixed Effects: We invoke the mean deviation algorithm by using the Stata command "xtreg, fe" (see Allison 2009, p. 12-13 for details). First, for each G1 grandparent and for each response and predictor variable that varies across cousins, the model computes the means across cousins for that G1 grandparent. Second, the model subtracts the G1 grandparent-specific means from the observed values of the response and predictor variables for each cousin to create $y_{i j}{ }^{*}$ and $x_{i j}{ }^{*}$, respectively. Last, the model regresses $y^{*}$ on $x^{*}$ (Allison, 2009).

- Predictor Variable: We follow previous multigenerational neighborhood studies (Sharkey and Elwert 2011; Sharkey 2013) which use a predictor that divides a continuous measure into bins. 